\title{
Effects of soil stratigraphy on pore-water flow in a creek-marsh system
}

\author{
Pei Xin ${ }^{1,2, \#}$, Jun Kong ${ }^{2}$, Ling $\mathrm{Li}^{1,2}$, D. A. Barry ${ }^{3}$ \\ ${ }^{1}$ National Centre for Groundwater Research and Training, School of Civil Engineering, The \\ University of Queensland, Queensland, Australia \\ Emails: p.xin@uq.edu.au, 1.1i@uq.edu.au \\ ${ }^{2}$ State Key Laboratory of Hydrology-Water Resources and Hydraulic Engineering, Hohai \\ University, Nanjing, China \\ Email: kongjun999@126.com \\ ${ }^{3}$ Laboratoire de technologie écologique, Institut d'ingénierie de l'environnement, Faculté de \\ l'environnement naturel, architectural et construit (ENAC), Ecole Polytechnique Fédérale de \\ Lausanne (EPFL), Station 2, 1015 Lausanne, Switzerland
} Email: andrew.barry@epfl.ch

Journal of Hydrology, Accepted 24 September 2012

\# Author to whom all correspondence should be addressed. Tel: +61 7 33469820. Email: p.xin@uq.edu.au 


\begin{abstract}
In coastal marshes, low-permeability mud is often found overlying high permeability sandy deposits. A recently developed 3D creek-marsh model was used to investigate the effects of soil stratigraphy (a mud layer overlying a sandy-loam layer) on pore-water flow in the marsh. Simulation results showed significant modifications of tide-induced pore-water flow due to the layered soil. The presence of the lower sandy-loam layer with a relatively high hydraulic conductivity not only increased the pore-water flow speed but also changed the flow direction, particularly in the upper mud layer where enhanced vertical flow dominated. Particle tracking revealed large changes in the overall pore-water circulation pattern, and associated particle travel path and time due to the influence of the soil stratigraphy. While the amount of water exchange between the marsh soil and tidal water increased, the residence time of particles in both soil layers was reduced. Sensitivity analysis showed the importance of soil compressibility, capillary rise and hydraulic conductivity contrast between the soil layers in modulating the effect of soil stratigraphy. In particular, the total net influx and efflux across the marsh surface (including the creek/channel bank and bed) increased proportionally with the square root of the lower layer's hydraulic conductivity. These results demonstrated the interplay of tides, marsh topography and soil stratigraphy in controlling the pore-water flow characteristics, which underpin solute transport and transformation as well as the aeration condition in the marsh soil.
\end{abstract}

Keywords: Salt marsh; Soil stratigraphy; Coastal wetland; Surface water and groundwater interaction; Tide 


\section{Highlights:}

$>\quad$ We examine pore-water flow in a two-layer (mud and sandy-loam) marsh.

$>\quad$ Flow in the two-layer marsh differs dramatically from that in a homogeneous marsh.

$>\quad$ The underlying sandy-loam layer modifies significantly the pore-water circulation.

$>\quad$ We examine effects of soil compressibility, capillarity and hydraulic conductivity.

\section{Introduction}

Coastal wetlands such as salt marshes have been increasingly recognized as an important and yet vulnerable ecosystem at the land-ocean interface, subjected to the threat of accelerating sea level rise due to global climate change (Fitzgerald et al., 2008). Better understanding of the complex wetland hydrology and hydrodynamics is needed to explore the wetlands' ecological functions (e.g., biodiversity support, water quality improvement and carbon cycling) and to predict their responses to climate change (Zedler and Kercher, 2005). The linkage between the hydrological and ecological processes has been the theme of many recent studies on salt marshes and other wetland systems (Cola et al., 2008; Li et al., 2005; Marani et al., 2006; Marani et al., 2007; Marani et al., 2010; Moffett et al., 2010; Moffett et al., 2012; Silvestri et al., 2005; Ursino et al., 2004; Wilson and Gardner, 2006; Xin et al., 2009; Xin et al., 2010; Xin et al., 2011). In particular, subsurface flow processes have been widely linked to two important hypotheses about salt marsh ecosystems: nutrient outwelling (Teal, 1962; Valiela and Teal, 1979) and plant zonation (Colmer and Flowers, 2008; Silvestri et al., 2005).

Numerical studies have demonstrated significant tidal effects on pore-water flow in the 
marsh soil (Fig. 1) (Wilson and Gardner, 2006; Xin et al., 2009; Xin et al., 2011). It has been shown that surface water infiltrates the soil through the marsh platform (i.e., the unchannelized marsh surface) when inundated by the rising tide while pore-water exfiltrates out of the marsh soil across the creek bank and bottom as the tide recedes. The intra-tidal groundwater dynamics exhibit significant flow asymmetry with non-zero mean flow velocities over the tidal period, leading to a circulating pore-water flow system near the creek. This local scale circulation provides a mechanism for more rapid solute exchange between the marsh soil and the hydraulically connected surface water, and ultimately affects the overall nutrient exchange between the marsh and coastal sea (Gardner, 2005; Wilson and Gardner, 2006; Xin et al., 2009; Xin et al., 2010; Xin et al., 2011). In conjunction with the pore-water circulation, the soil aeration condition is improved near the creek (Li et al., 2005; Ursino et al., 2004; Xin et al., 2009; Xin et al., 2010). For aeration-dependent marsh plants such as Spartina alterniflora (Colmer and Flowers, 2008; Mendelssohn et al., 1981), the near-creek circulation can thus affect positively plant root respiration and growth, resulting in a zone of enhanced vegetation near the creek (Howes et al., 1981; Howes and Goehringer, 1994; Mendelssohn et al., 1981).

So far, modeling studies have been largely based on 2D (two-dimensional) vertical sections perpendicular to marsh creeks (Gardner, 2005; Li et al., 2005; Marani et al., 2006; Ursino et al., 2004; Wilson and Gardner, 2006; Xin et al., 2009; Xin et al., 2010) that neglect the system's spatial variability and flow in the along-creek direction. Exceptions are the recent studies of Xin et al. (2011) and Moffett et al. (2012). Xin et al. (2011) developed a 3D creek-marsh model and investigated tidally driven pore-water flow in the marsh soil, interacting with a creek embedded 
in the marsh bordered by a tidal main channel (Fig. 1). They demonstrated strong 3D behavior of both intra-tidal pore-water flow and tidally averaged circulations, which are linked to the marsh topography over three key spatial scales: near the creek bank, around the creek meander and over long marsh sections inclined towards the main channel. Particle tracking revealed that time scales associated with the circulations at the three spatial scales differed by orders of magnitude. Two discharge zones linked to the creek and main channel, respectively, were identified (Xin et al., 2011). As shown in Fig. 2, these two discharge zones represent two different chemical pathways through the creek-marsh system. As the main channel is connected hydraulically to the adjacent coastal sea, it plays an important role not only for transmitting tidal signals, but also for chemical transport between the marsh and coastal sea. With respect to chemicals (nutrients) sourced from the marsh soil, circulating pore-water flows are directly responsible for generating fluxes of these chemicals across the marsh surface. Mass flux associated with drainage of pore-water at the main channel $\left(Q_{1}\right)$ represents a direct input to the channel. In contrast, mass flux driven by pore-water discharge to the creek $\left(Q_{2}\right)$ would be subjected to further transport and reactions (for reactive chemicals) within the creek surface water prior to entering the main channel $\left(Q_{3}\right)$. The mass fluxes at both the main channel and creek depend on the chemical concentrations at the outlet $(C)$, which in turn vary with the paths and travel times $(T)$ associated with the circulating pore-water flows. The efflux via the creek to the main channel would be influenced further by the transport pathways and travel times of chemicals in the creek surface water.

The study by Xin et al. (2011) was based on a marsh model composed of homogeneous 
sandy-loam. In reality, most marshes possess soil stratigraphy: commonly, low-permeability mud and/or silt loam are found to overlie sands or sandy-loam deposits in these wetlands (Fig. 1) (Carol et al., 2011; Dolphin et al., 1995; Gardner and Porter, 2001; Harvey et al., 1987; Hughes et al., 1998; Perillo et al., 2005; Xin et al., 2009). Based on 2D models of vertical cross-creek sections, Gardner (2007), Xin et al. (2009) and Wilson and Morris (2012) simulated pore-water flow in two-layer marsh soils as discussed above. These studies showed that the total seepage flux from the two-layer marsh soil to the creek is larger than that from a homogeneous mud marsh. The underlying sandy-loam layer enhances the pore-water circulation through the marsh. These studies also suggest that the presence of the sandy-loam layer lowers the groundwater table in the upper mud layer and hence improves local soil aeration conditions.

Although Gardner (2007), Xin et al. (2009) and Wilson and Morris (2012) have demonstrated significant effects of soil stratigraphy on pore-water flow within 2D cross-creek sections, how soil stratigraphy modulates the pore-water circulation in a realistic, 3D marsh system remains an important question. This paper aims to address this question by examining the combined effects of marsh topography and soil stratigraphy on pore-water flow in a synthetic 3D marsh. The model of Yuan et al. (2011) was used to simulate coupled surface water and groundwater flow within the modeled marsh system. To account for the effect of varying total stress during inundation of the marsh platform, the SUTRA (Voss and Provost, 2008) code for groundwater flow modeling was modified by incorporating a tidal loading term into the governing Richards equation (Reeves et al., 2000). Particle tracking was used to elucidate the simulated flow characteristics, in particular, pore-water circulation paths related to the tidally 
averaged flow and associated travel times. Sensitivity analysis was conducted to examine the effects of soil stratigraphy with different hydraulic conductivity contrasts between the two (upper and lower) soil layers, and with different soil compressibility and capillary rise.

\section{Conceptual and mathematical models}

\subsection{Physical conditions}

The topography of the modeled marsh was similar to that of the base case in Xin et al. (2011). The creek-marsh system, capturing features of typical upper sections of tidal flats (Allen, 2000; Novakowski et al., 2004; Torres and Styles, 2007), was characterized by topographic (slope) changes over three different scales: (1) large slopes at the creek and main channel bank ( 0.2 and 0.1 , respectively), (2) marsh surface elevation changes associated with the creek meander (with a

maximum channel curvature of $\pi^{2} / 500 \mathrm{~m}^{-1}$ ), and (3) a small uniform inclination angle (slope of 0.005) over the whole marsh platform (Fig. 1; see Xin et al. (2011) for further details).

The marsh domain was divided into two layers: an upper low-permeability mud layer and a lower high-permeability sandy-loam layer. In real marshes, the interface between the two soil layers is likely to vary spatially and temporally (Hughes et al., 1998; Xin et al., 2009). For the purpose of simplicity, we set the interface between the two soil layers locally at a depth (from the marsh platform) equivalent to $10 \%$ of the sediment thickness (Fig. 1). This depth is essentially the thickness of the upper mud layer. As the elevation of the marsh platform and hence the sediment thickness in the model increased from 6 (seaward marsh edge) to $7.25 \mathrm{~m}$ (marsh upper end), this interface varies in depth from 0.6 to $0.725 \mathrm{~m}$. This stratigraphy is consistent with field 
observations (Hughes et al., 1998; Xin et al., 2009).

A single-constituent, sinusoidal tide was specified at the main channel boundary (Fig. 1) to drive surface water and groundwater flow in the model, i.e.,

$$
h(t)=Z_{\mathrm{MSL}}+A \cos (\omega t),
$$

where $h(t)$ is the specified tidal water level [L] at time $t[\mathrm{~T}] ; Z_{\mathrm{MSL}}$ is the mean sea level [L] (set to $6.3 \mathrm{~m}$ ); and $A$ and $\omega$ are the tidal amplitude [L] (set to $1 \mathrm{~m}$ ) and angular frequency $\left[\mathrm{T}^{-1}\right]$ (set to $\pi / 6 \mathrm{rad} / \mathrm{h}$; semi-diurnal solar tide), respectively.

\subsection{Mathematical model}

As mentioned above, a coupled model based on ELCIRC for surface water flow (Zhang et al., 2004) and SUTRA for pore-water flow (Voss and Provost, 2008) was employed to simulate the interactions between surface water and groundwater in the modeled creek-marsh system driven by the tide. The details of the coupling approach and model validation can be found in Yuan et al. (2011). SUTRA was modified with a tidal loading term added to the governing Richards' equation (RE) for the variably saturated pore-water flow in the marsh soil to account for the effects of varying total stress (Gardner and Wilson, 2006; Reeves et al., 2000).

The original form of RE used in SUTRA is (Voss and Provost, 2008),

$$
\frac{\partial\left(\phi S_{W}\right)}{\partial t}+S_{W} S_{S} \frac{\partial \Phi}{\partial t}=\nabla \cdot[K(\psi) \nabla \Phi]+Q_{\mathrm{V}} \text { with } \Phi=\frac{P}{\rho g}+z
$$

where $K(\psi)$ is the hydraulic conductivity $\left[\mathrm{LT}^{-1}\right]$, depending on the capillary pressure head, $\psi$ $[\mathrm{L}] ; S_{W}$ is the soil water saturation [-]; $\phi$ is the soil porosity [-]; $\Phi$ is the hydraulic head [L]; $P$ is the pore-water pressure $\left[\mathrm{ML}^{-1} \mathrm{~T}^{-2}\right],=\psi$ for the unsaturated zone; $Q_{\mathrm{V}}$ is the source/sink 
term $\left[\mathrm{T}^{-1}\right] ; g$ is the magnitude of the gravitational acceleration $\left[\mathrm{LT}^{-2}\right] ; \quad \rho$ is the fluid density $\left[\mathrm{ML}^{-3}\right]$; and $S_{S}$ is the specific storativity $\left[\mathrm{L}^{-1}\right]$. In SUTRA, the specific storativity is (Bear, 1979),

$$
S_{S}=\rho g[(1-\phi) \alpha+\phi \beta]
$$

where $\alpha \quad\left[\mathrm{M}^{-1} \mathrm{LT}^{2}\right]$ and $\beta \quad\left[\mathrm{M}^{-1} \mathrm{LT}^{2}\right]$ are, respectively, the compressibility coefficients for soil matrix and water. The storativity term in Eq. (2) accounts for the storage change due to the compressibility of soil matrix and water, assuming constant total stress on the soil skeleton (Voss and Provost, 2008). When the marsh is flooded at high tide, fluctuations of pore-water pressure with varying overlying water depth would lead to changes of effective stress under the assumption of constant total stress, generating an artificial pressure wave through the elastic soil. Consequently, an artificial flux would occur at the boundary flooded (Gardner and Wilson, 2006). Physically, the total stress on the soil skeleton is not constant during the flooding but varies in the same way as the pore-water pressure, thus giving approximately an invariant effective stress (i.e., no expansion or contraction of soil matrix). To account for the total stress variation and remove the artificial flux, a tidal loading term needs to be incorporated into RE (Gardner and Wilson, 2006; Reeves et al., 2000; Wilson and Morris, 2012; Yuan et al., 2011),

$$
\frac{\partial\left(\phi S_{W}\right)}{\partial t}+S_{W} S_{S} \frac{\partial \Phi}{\partial t}=\nabla \cdot[K(\psi) \nabla \Phi]+S_{W}(1-\phi) \alpha \frac{\partial \sigma_{\mathrm{T}}}{\partial t}+Q_{\mathrm{V}}
$$

where $\sigma_{\mathrm{T}}$ is the total stress $\left[\mathrm{ML}^{-1} \mathrm{~T}^{-2}\right]$ and $\partial \sigma_{\mathrm{T}} / \partial t=\rho g \partial D / \partial t$ with $D$ being the local surface water depth, i.e., local surface water level - local marsh surface elevation [L]. If the calculated $D$ is less than zero, the local marsh surface is exposed (i.e., under a constant total 
stress) and then the tidal loading term is no longer needed (i.e., $\left.\partial \sigma_{\mathrm{T}} / \partial t=0\right)$. Following the approach of Reeves et al. (2000), the tidal loading term was incorporated into SUTRA (Voss and Provost, 2008) as a source or sink. Note that SUTRA models mass flux and thus volumetric flux needs to be multiplied by the fluid density $\left(\rho\left[\mathrm{ML}^{-3}\right]\right)$ in computing the source/sink. For each node (indicated here by a superscript $i$ ) vertically beneath the overlying surface water, a mass flux $\left(Q_{\mathrm{M}}\right)$ related to the tidal loading was incorporated as follows,

$$
Q_{\mathrm{M}}^{i}=(1-\phi) \alpha \rho V^{i} S_{W}^{i} \frac{\partial \sigma_{\mathrm{T}}^{i}}{\partial t}=(1-\phi) \alpha \rho V^{i} S_{W}^{i} \frac{\partial\left(\rho g D^{i}\right)}{\partial t}
$$

where $V^{i}\left[\mathrm{~L}^{3}\right]$ is the control volume related to node $i$. Following Reeves et al. (2000), we tested the modified code by considering a simple "piston and spring" problem (i.e., compressibility-induced flow in a saturated soil column subjected to a sinusoidal tide). The predicted flux across the boundary was found to agree well with the analytical solution given in Reeves et al. (2000) (results not shown), confirming that the modification to the SUTRA code was appropriate.

It should be noted that both the surface water and groundwater flow models are capable of simulating solute transport and its coupling with the flow, i.e., flow influenced by density gradients due to variations of solute concentrations. In coastal marshes, salt concentrations in surface water and pore-water tend to vary spatially and temporally, leading to density gradients that may affect the pore-water flow. While the model could simulate such effect, we chose to neglect it by assuming a constant water density, as done in previous numerical studies (Ursino et al., 2004; Wilson and Gardner, 2006; Xin et al., 2009; Xin et al., 2010), in order to focus on 
marsh topography and soil stratigraphy in the first instance.

\subsection{Parameters values used in the simulations}

Silt loam (mud) and sandy-loam, two typical soil types commonly encountered in salt marshes, were used as the simulated marsh soils (Simonini and Cola, 2002). The soil in each layer was assumed to be homogeneous and isotropic. According to Wang et al. (1997), the saturated hydraulic conductivities of upper (mud) and lower (sandy-loam) soil layers were set to $1.25 \times 10^{-6} \mathrm{~m} / \mathrm{s}$ and $1.23 \times 10^{-5} \mathrm{~m} / \mathrm{s}$, respectively. The corresponding porosities were 0.45 (upper) and 0.41 (lower). For the upper soil layer, the residual water saturation, $S_{W r e s}$, was set to be 0.15 , and the van Genuchten (1980) water retention parameters (for calculating the soil water saturation and hydraulic conductivity based on local capillary pressure; see details in Yuan et al. (2011)), $\alpha_{v}$ and $n$, to $2 \mathrm{~m}^{-1}$ and 1.41 , respectively, according to the data for the soil type given by Carsel and Parrish (1988) (Case 1 in Table 1). The lower soil layer was expected to be (near-) saturated over the tidal period. Therefore, the parameter values used for the unsaturated flow simulation did not affect the flow in the lower layer. Compressibility of the soil matrix and water were, respectively, $10^{-7} \mathrm{~Pa}^{-1}$ and $4.47 \times 10^{-10} \mathrm{~Pa}^{-1}$ (Freeze and Cherry, 1979).

For comparison, a homogeneous marsh was also simulated (Case 3 in Table 1). For both the homogeneous and two-layer marshes, we also ran simulations with compressibility neglected (Cases 2 and 4 in Table 1), giving four base-case simulations. Simulations with different degrees of soil compressibility, capillary rise and hydraulic conductivity contrast between the two soil layers were also conducted to facilitate sensitivity analyses. 
The initial and boundary conditions were the same as those used by Xin et al. (2011). Similar time step sizes were also used (a time step of $10 \mathrm{~s}$ was used in the groundwater model). The mesh used in Xin et al. (2011) was locally refined by a factor of 4 in the vertical direction (giving vertical element size around $0.05 \mathrm{~m}$ ) for the upper layer. We checked, via mesh and time-step refinement, that converged results are presented below.

\section{Simulation results}

\subsection{Temporal dynamics and spatial variations of pore-water flow}

The pore-water flow in the modeled two-layer marsh was generally $3 \mathrm{D}$ and varied with the tide, particularly in the areas near the creek and main channel. For both the layered and homogeneous marsh, simulated intra-tidal groundwater dynamics exhibited flow asymmetry with non-zero mean flow velocities over the tidal period. We focus here on the tidally averaged flow, which controlled the net water movement and solute exchange between the marsh soil and creek/main channel.

To examine the effects of soil stratigraphy in detail, we selected two vertical sections: one across the creek and mid-way up from the main channel (at $y=100 \mathrm{~m}$, Fig. 3), and the other perpendicular to the main channel and $10 \mathrm{~m}$ from the left boundary (at $x=-40 \mathrm{~m}$, Fig. 4 ). The tidally averaged flow was characterized by infiltration through the marsh platform, and drainage across the creek bank and bottom as well as the main channel bank (Figs. 3 and 4). This formed pore-water circulations near both the creek bank and the main channel bank, which is in agreement with results from previous 2D (Wilson and Gardner, 2006; Xin et al., 2009) and 3D 
(Xin et al., 2011) modeling work.

In the homogeneous marsh, pore-water flow developed mainly within $10 \mathrm{~m}$ of the creek (Fig. 3a). The flow weakened with increasing distance from the creek, consistent with the attenuation of associated tidal groundwater waves. With the presence of the lower sandy-loam layer, the flow in the marsh soil was enhanced. Relatively strong pore-water flow developed further than $10 \mathrm{~m}$ away from the creek, within not only the lower sandy-loam layer but also the upper mud layer, where increased downward drainage was clearly evident (Fig. 3b). This effect can be seen more clearly in Fig. 5 where flow velocities are plotted for two observation points: one in the upper layer away from the creek and another in the lower layer under the creek bank. In the upper layer, the magnitude of the local flow increased with the presence of the underlying sandy-loam layer, particularly the velocity in the vertical direction (Fig. 5). At the corresponding observation point in the homogeneous mud marsh, the cross-channel flow velocity $\left(v_{y}\right)$ had a larger magnitude than that of the cross-creek $\left(v_{x}\right)$ and vertical flow velocities $\left(v_{z}\right)$ during the exposure of the local marsh surface. In contrast, the flow at this location in the layered marsh was predominantly vertical (downward), indicating drainage of pore-water from the upper to the lower layer. The flow in the lower layer was also intensified even though it was mainly horizontal, as in the homogeneous marsh. This indicated that a significant amount of pore-water drained from the upper layer was discharged into the creek and main channel through the underlying conductive soil, where the flow was active, particularly in the cross-creek direction $\left(v_{x}\right.$, Fig. 5e). The mechanism of preferential flow through the lower layer was suggested by Gardner (2007), Xin et al. (2009) and Wilson and Morris (2012), and was thought to influence the overall interaction between surface 
water and groundwater (results given in $\S 3.3$ ).

For the base cases, the compressibility of the soil matrix and water did not appear to affect the flow dynamics to any extent. The flow fields simulated with and without compressibility largely overlapped (Figs. 3 and 4). The effects of compressibility are further examined in $\S 4.1$.

\subsection{Particle traces and associated travel times}

Based on the tidally averaged pore-water flow, we examined the traces and travel times of passive particles moving through the marsh soil. The trace tracks the particle's movement in the marsh sediment from the release point (at a selected location on the marsh surface) to the exit while the travel time measures the duration of the movement (Robinson et al., 2007; Zimmerman, 1976). Particles were released uniformly across the marsh surface to the surface soil layer at a depth of $0.1 \mathrm{~m}$. Thus, the results represent the behavior of both "skin circulation" near the sediment surface and "body circulation" that occurred underneath the surface layer as proposed by Billerbeck et al. (2006).

For both the homogeneous mud marsh (Case 3) and the two-layer marsh (Case 1), the particle travel paths displayed 3D pore-water flow patterns linked strongly to the marsh topography, over a range of spatial scales: near the creek bank, around the creek meander and over long marsh sections inclined towards the main channel (Fig. 6). The effects of soil stratigraphy on the flow were manifested with significant modifications of the particle travel paths (Figs. 6 and 7). In particular, the exit locations of the paths changed (1) from a downstream creek section to an upstream section (particle A), (2) from the creek to the main channel and vice 
versa (particles B and C), and (3) from the marsh surface to the main channel (particle D). Associated with the changes of the exit locations were large variations of the actual pathways and particle travel times; however, these variations were mixed with both lengthening and shortening effects taking place in different areas (Figs. 6 and 7).

Overall the particle travel time exhibited large spatial variations by orders of magnitude, with small travel time occurred near the creek in both the homogeneous mud marsh (Case 3) and the two-layer marsh (Case 1) (Figs. 7c and 7d). Due to the high hydraulic conductivity of the lower sandy-loam, the particle travel time in the two-layer marsh was significantly shorter on average. The patterns of the spatial travel time variations were largely similar in both cases, dominated by the influence of the meandering creek. However, major differences existed in two areas. In the upper inner marsh area near the top right corner and the lower inner marsh area near the low left corner (Fig. 7b), particles took relatively short travel paths in the homogeneous mud marsh. As shown in Fig. 6, these particles traveled initially a distance towards the main channel, but quickly moved upward and out across the sediment surface, undergoing only a relatively short (in time and distance) "skin circulation". Billerbeck et al. (2006) suggested that "skin circulation" near the sediment surface is induced mainly by local topographic variations, at relatively small scales. However, such a circulation in our modeled marsh with a plane platform was instead induced by the seepage face flow, which occurred across the sediment surface during the falling tide (Xin et al., 2011). This "skin circulation" vanished in the two-layer marsh system. Due to the presence of an underlying conductive layer, the vertical flow in the mud layer was significantly enhanced, resulting in particles taking deeper and longer travel paths to exit from 
the main channel bank (Fig. 6) after relatively long travel times.

To examine further the effect of soil stratigraphy, the distributions of particle travel times were calculated (Fig. 8). Travel times were considered separately for the "upper" and "lower" layer sections, and the whole marsh system in both the homogeneous and two-layer marsh cases. Due to the relatively high conductivity of the lower sandy-loam layer, the majority of particles $(70 \%)$ moved through both layer sections. Overall, movement was approximately ten times faster in the two-layer marsh than in the homogeneous mud marsh. The difference made by the simulated soil stratigraphy showed a consistent effect but was less profound for fast moving particles (about 30\%) initially released near the creek and main channel. Ninety-one percent of the released particles were found to have travelled through the layered marsh sediment within $10^{4}$ days, in comparison with only $44 \%$ of the particles moving through the homogeneous mud marsh over the same period (Fig. 8). In the "upper layer" section, the particle travel times in the two-layer marsh were reduced significantly from those in the homogeneous mud marsh, especially for slowly moving particles associated with areas away from the creek and main channel (Fig. 8). Overall, particles in the two-layer marsh system spent most time in the lower layer. In contrast, it took particles much longer to travel through the "upper layer" section in the homogeneous marsh, comparable with the travel time in the "lower layer" section. For particles undergoing the "skin circulation" (13\%), the "lower layer" section was bypassed.

The above particle tracking results illustrated not only the pore-water flow patterns but also provided information about the extent of contact between pore water/solute and soil grains in different "layer" sections, both affected significantly by the soil stratigraphy. Here we investigate 
the case where the two (mud and sandy-loam) layers possess different chemical characteristics. The particle tracking results suggest that in the two-layer marsh, solutes move more quickly into the lower sandy-loam layer, interacting less with perhaps the more reactive soil in the upper mud layer. This may affect considerably the fate of solutes transported through the marsh soil. In summary, while the presence of the sandy-loam layer enhanced the exchange in terms of water flux between the marsh soil and tidal water, solutes in the pore-water might be less modified by reactions with marsh soils before discharging into coastal water.

\subsection{Fluxes across the surface water and groundwater interface}

The presence of the lower sandy-loam layer with a relatively high hydraulic conductivity was shown above to enhance the tide-induced flow in the marsh soil, especially in the upper mud layer where the vertical infiltration was increased. Based on the simulated flow, the net flux across the marsh surface was calculated along the transect $y=100 \mathrm{~m}$ as shown in Fig. 3. The results showed influx through the marsh surface accompanied by efflux across the creek bank and bed in both the homogeneous and the two-layer marshes (Fig. 9). However, the magnitudes of influx and efflux both increased in the two-layer marsh as a consequence of the enhanced flow. While the changes of local efflux across the creek seemed to be proportional (linear) with the increase of the flux magnitude at the creek bed, the difference in the influx between the two marsh systems appeared to be more distinctive. In the homogenous marsh, the influx concentrated in the near-creek area as indicated by the local concave flux variation. In contrast, significant influx occurred more over a larger area in the two-layer marsh (with a linear flux 
variation). This effect was demonstrated by the difference between the two systems in the area (from the creek) where $80 \%$ of the total influx occurred, which increased from $32 \mathrm{~m}^{3} / \mathrm{m}^{2}$ in the homogeneous marsh to $60 \mathrm{~m}^{3} / \mathrm{m}^{2}$ the two-layer marsh (Fig. 9).

For both marsh types, temporal variations of the total water flux across the interface over the whole marsh area were similar to that of the base case in Xin et al. (2011), except for the flux magnitude (Fig. 10). Drainage (efflux) occurred during the exposure period while the surface water recharged (influx) the soil mainly during the submergence. With the presence of the lower sandy-loam layer, the total exchange between surface water and groundwater increased by three times $\left(14.12 \mathrm{~m}^{3}\right.$ per tidal cycle in the two-layer marsh compared with $4.67 \mathrm{~m}^{3}$ per tidal cycle in the homogeneous marsh; Table 1).

As shown earlier, pore-water undergoing tide-induced circulation in the marsh mainly exited at the meandering creek and main channel, resulting in net efflux over the tidal period (Table 1 and Fig. 11). While the efflux magnitude changed case-by-case, the spatial variation of efflux along the creek or main channel did not exhibit any characteristic difference. The local net efflux, influenced slightly by the creek channel curvature, varied along the creek and produced a total discharge nearly proportional to the creek length. The net efflux to the creek dominated the total net efflux (by comparison with that to the main channel), suggesting a key role played by the near-creek circulation. However, as the lower soil layer changed from mud to sandy-loam, the ratio of net efflux to the creek to that to the main channel decreased from 9.1 to 4.9. In other words, the presence of the sandy-loam increased the influence of the main channel in draining the marsh soil. The total net efflux increased from $3.74 \mathrm{~m}^{3}$ in Case 3 to $11.59 \mathrm{~m}^{3}$ in Case 1 , by a 
factor of 3.09 , which is consistent with the relative change of square root of lower soil layer's

hydraulic conductivity, $\sqrt{K_{\text {lower }}}$ (i.e., $\sqrt{1.23 \times 10^{-5} / 1.25 \times 10^{-6}}=3.16$ ). Further analyses and discussion on the net efflux are given in $§ 4.3$.

\section{Sensitivity analyses and discussion}

Focusing on the net efflux to the creek and main channel over the tidal period, we conducted sensitivity studies to assess the importance of soil compressibility, capillary rise and hydraulic conductivity contrast between the two soil (mud and sandy-loam) layers.

\subsection{Importance of soil matrix compressibility}

The water compressibility $\left(\sim 4.47 \times 10^{-10} \mathrm{~Pa}^{-1}\right)$ is much less than that of the soil matrix and hence does not affect significantly the pore-water flow. For both Cases 1 and 3, the relatively small soil compressibility $\left(10^{-7} \mathrm{~Pa}^{-1}\right)$ applied in the simulation did not influence much the net effluxes along the creek and main channel (Fig. 12a), compared with the results from the simulations assuming negligible soil compressibility. This minor effect was also evident in the results of the simulated (tidally averaged) flow field (Figs. 3 and 4) and fluxes across the surface water and groundwater interface (Figs. 9 and 10). Cases 1 and 3 with compressibility produced fluxes that were slightly higher than those without compressibility (Cases 2 and 4 listed in Table 1). Furthermore, the peak of drainage was slightly lagged due to the influence of compressibility (Fig. 10).

When the soil compressibility increased from $10^{-7} \mathrm{~Pa}^{-1}$ to $10^{-6} \mathrm{~Pa}^{-1}$, the model predicted a similar net efflux over the tidal period for the homogeneous mud marsh. However, the total net 
efflux in the two-layer marsh system increased significantly from $11.59 \mathrm{~m}^{3}$ to $13.96 \mathrm{~m}^{3}$ (Fig. 12a). Such a significant change, also evident in Fig. 9, was likely related to the two-layer soil configuration, particularly with a more conductive layer underneath. Generally, the variations of storage in an unconfined groundwater system are two-fold: volumetric change due to saturation/de-saturation processes and elastic storage/release due to the deformation of soil skeleton (i.e., soil compressibility). The former is largely affected by the groundwater table fluctuation while the latter acts as a source/sink term induced by the varying effective stress associated with pore-water pressure changes. For the homogeneous low-permeability mud marsh examined here, propagation of the tide-induced groundwater wave was limited in the soil ( $L i$ et al., 2000), leading to only a small amount of drainage over the tidal cycle. For this condition, the marsh interior was largely saturated, with total hydraulic head remaining close to the sediment surface during exposure. Although the local pore pressure during the overtopping varied in pace with the level of the overlaying surface water, the total stress also varied similarly to cancel out any changes in the effective stress. With a relatively steady effective stress condition, the soil compressibility generated negligible storage variations or flow in the marsh soil. In contrast, the presence of the underlying sandy-loam in the two-layer system led to enhanced groundwater wave propagation in the marsh soil, with increased ranges of pressure and effective stress fluctuations (Xin et al., 2009). Under such a condition, the soil compressibility, once it exceeded a certain level (e.g., $10^{-6} \mathrm{~Pa}^{-1}$ ), started to play a significant role in influencing the pore-water flow and associated flux.

Natural marshes, composed of silt and silt-loam, tend to be highly compressible (Hemond 
and Fifield, 1982). The results from this sensitivity analysis suggest that soil compressibility needs to be considered properly in modeling the behavior of these wetland systems, particularly those with layered soil structures. Moreover, the model needs to incorporate the tidal loading term to account for the total stress variations during overtopping of the marsh platform (Gardner and Wilson, 2006; Reeves et al., 2000; Wilson and Morris, 2012).

\subsection{Importance of capillary rise}

The effects of capillary rise were also examined based on the two-layer marsh (in comparison with Case 1). As the lower soil layer was expected to be largely saturated, we focused on the capillary properties of the upper soil layer by varying parameter values for $\alpha_{v}$, which is inversely proportional to the capillary rise height (Parlange and Brutsaert, 1987). The results show that the net efflux to the creek and main channel increased with $\alpha_{v}$ (Fig. 12b). For this case, the marsh soil near the surface underwent increased drainage on the falling tide. The enhanced drainage in turn permitted more water to infiltrate the marsh during the overtopping on the subsequent tide, resulting in an increase in both net influx and efflux. This effect demonstrated further the important role of the unsaturated flow in affecting the marsh soil condition, being directly responsible for recharge and drainage of the shallow groundwater in the marsh soil (Xin et al., 2011).

As capillary rise increases, an extensive, largely saturated capillary fringe exists above the groundwater table. Then, water rather than air occupies most of the pore space in the upper soil layer where plant roots are distributed. This reduces soil aeration and adversely affects plant 
growth in the salt marsh (Colmer and Flowers, 2008).

\subsection{Importance of hydraulic conductivity}

Simulations were also conducted for marshes of the same layer configuration but with varying hydraulic conductivity contrasts between the soil layers $\left(K_{\text {lower }} / K_{\text {upper }}\right)$ via increasing $K_{\text {lower. }}$ As the contrast increased, the net efflux to both the creek and main channel increased significantly (Fig. 12c). This result is consistent with the findings of Gardner (2007) and Xin et al. (2009), both based on 2D marsh systems.

The total net efflux was linearly correlated $\left(R^{2}=0.99\right)$ with $\sqrt{K_{\text {lower }}}$ (Fig. 13). This correlation is consistent with the theory of groundwater wave propagation in an aquifer (e.g., Barry et al., 1996; Bear, 1979; Jeng et al., 2005; Li et al., 2000; Parlange et al., 1984; Teo et al., 2003), which predicts a square-root relationship between the characteristic wave length $(\lambda)$ and aquifer hydraulic conductivity $\left(K_{s}\right)$, i.e., $\lambda \propto \sqrt{K_{S}}$. The wave theory also predicts that the magnitude of the hydraulic gradient associated with the groundwater wave is inversely related to the wave length $(1 / \lambda)$. This, upon the application of Darcy's law, leads to a relationship of flux proportional to the square root of $K_{s}$. For the modeled marsh system, the lower soil layer behaved like a semi-confined aquifer bounded by a low-permeability soil layer on the top. The groundwater wave propagated more extensively in the lower layer, which in turn affected the flow and flux in the upper layer and the whole marsh system. Based on the groundwater wave theory described above, it is expected that the net efflux from the marsh soil over the tidal period would depend on $\sqrt{K_{\text {lower }}}$. 
For the cases simulated, a larger efflux rate occurred at the creek bank with a relatively steep slope than at the mildly sloping main channel bank. As discussed earlier in relation to the results of Fig. 11, the presence of the lower high-permeability layer reduced the influence of the creek relative to the main channel. This effect was manifested further here with a trend of decreasing ratio of net efflux to the creek to that to the main channel as the hydraulic conductivity of the lower soil layer increased (Fig. 13).

\section{Conclusions}

Soil stratigraphy with a low-permeability mud layer overlying a high-permeability sandy-loam layer is a common feature of many natural salt marshes. We have examined numerically the effects of such soil stratigraphy on pore-water flow in a 3D creek-marsh system. The results highlighted strong 3D flow characteristics linked to the marsh topography, similar to those in a homogeneous marsh. However, the presence of the lower sandy-loam layer with a relatively high hydraulic conductivity not only increased significantly the magnitude of the pore-water flow velocity but also changed the flow direction, particularly in the upper mud layer where enhanced vertical flow dominated. In contrast, the comparison simulation based on a homogeneous marsh showed that for marshes composed of low-permeability soil without an underlying highly conductive layer, the tide-induced drainage is relatively weak. Under such a condition, the marsh system may become more like an upland wetland, affected largely by rainfall and evapotranspiration (Marani et al., 2006).

The pore-water flow characteristics revealed in this study have the following implications 
for future investigations of marsh eco-hydrology:

(1) Soil stratigraphy is an important factor in determining pore-water flow, and solute transport and transformation in the marsh soil. The presence of an underlying sandy-loam layer modifies water fluxes across the marsh surface, which in turn may affect the total solute exchange between the marsh and coastal water. Since the vertical flow increased significantly in the upper layer, solutes move more quickly into the lower sandy-loam layer as indicated by the particle tracking results. This suggests that the solutes may interact less with the possibly more reactive soil in the upper mud layer, which would affect the fate of solutes in the soil and fluxes across the marsh surface.

(2) The presence of the underlying sandy-loam layer enhances the drainage of the marsh soil, especially the upper layer, during the falling tide. This is likely to lead to a reduction of local soil water saturation and hence improved aeration of the top soil layer, favoring plant growth.

(3) Soil compressibility, when combined with soil stratigraphy, is also an important factor which should be accounted for in quantifying pore-water flow in the marsh soil. With increased pore-water pressure fluctuations due to the soil stratigraphy, elastic storage/release associated with soil compressibility becomes an important part of the local water budget in the soil and hence affects considerably the pore-water flow.

It should be pointed out that burrows produced by invertebrates (e.g., crabs) are also commonly found in salt marshes. These macro-pores, together with the two-layer marsh configuration, present even more complex soil heterogeneity. The burrows can penetrate through 
the upper soil layer and provide preferential flow paths to the lower conductive layer (Xin et al., 2009). In essence, the lower sand-loam layer also acted as a preferential flow path in the modeled marsh considered here. How this large scale preferential flow path interacts with others at local scales to affect the pore-water flow and solute transport in the soil within the whole marsh system remains an open question.

There are other aspects of the system's complexity that have not been considered in this study. In real salt marshes, the interface between the two soil layers (silt loam and sandy loam) is likely to vary spatially and temporally. The salinity in the surface water and pore-water may vary spatially and temporally due to, for example, influence of rainfall and evapotranspiration (Cao et al., 2012). This would lead to density-dependent flow in both surface water and pore-water. Natural marsh soils can be hydraulically anisotropic, which would affect the pore-water flow pattern as found in a lake-groundwater system (Pfannkuch and Winter, 1984; Winter and Pfannkuch, 1984). All these factors, reflecting the complexity of the marsh system, present directions for future research to improve fundamental understanding of eco-hydrological processes underlying the behavior of marsh eco-systems. The present study provides a starting point for such research.

\section{Acknowledgments}

This research was supported by the Australian Research Council (DP0988718). P. X. acknowledges an Early Career Researcher Grant provided by The University of Queensland (603275) and an Open Fund of State Key Laboratory of Hydrology-Water Resources and 
Hydraulic Engineering provided by Hohai University (2010491111). JK acknowledges the National Natural Science Foundation of China (51009059). 


\section{References}

Allen, J.R.L., 2000. Morphodynamics of Holocene salt marshes: A review sketch from the Atlantic and Southern North Sea coasts of Europe. Quaternary Science Reviews 19 (12), 1155-1231, doi:10.1016/S0277-3791(99)00034-7.

Barry, D.A., Barry, S.J., Parlange, J.-Y., 1996. Capillarity correction to periodic solutions of the shallow flow approximation, In Mixing Processes in Estuaries and Coastal Seas, C. B. Pattiaratchi (editor), Coastal and Estuarine Studies, Volume 50, American Geophysical Union, Washington, DC, USA, pp. 496-510.

Bear, J., 1979. Hydraulics of Groundwater, McGraw-Hill, New York, USA.

Billerbeck, M., Werner, U., Polerecky, L., Walpersdorf, E., deBeer, D., Huettel, M., 2006. Surficial and deep pore water circulation governs spatial and temporal scales of nutrient recycling in intertidal sand flat sediment. Marine Ecology Progress Series 326, 61-76, doi: $10.3354 /$ meps326061.

Blum, L.K., 1993. Spartina alterniflora root dynamics in a Virginia marsh. Marine Ecology Progress Series 102, 169-178, doi: 10.3354/meps102169.

Cao, M., Xin, P., Jin, G., Li, L., 2012. A field study on groundwater dynamics in a salt marsh Chongming Dongtan wetland. Ecological Engineering 40, 61-69, doi: 10.1016/j.ecoleng.2011.12.018.

Carol, E.S., Kruse, E.E., Pousa, J.L., 2011. Influence of the geologic and geomorphologic characteristics and of crab burrows on the interrelation between surface water and groundwater in an estuarine coastal wetland. Journal of Hydrology 403 (3-4), 234-241, 
doi:10.1016/j.jhydrol.2011.04.007.

Carsel, R.F., Parrish, R.S., 1988. Developing joint probability distributions of soil water retention characteristics. Water Resources Research 24 (5), 755-769, doi:10.1029/WR024i005p00755.

Cola, S., Sanavia, L., Simonini, P., Schrefler, B., 2008. Coupled thermohydromechanical analysis of Venice lagoon salt marshes. Water Resources Research 44, W00C05, doi:10.1029/2007WR006570.

Colmer, T.D., Flowers, T.J., 2008. Flooding tolerance in halophytes. New Phytologist 179 (4), 964-974, doi:10.1111/j.1469-8137.2008.02483.x.

Dolphin, T.J., Hume, T.M., Parnell, K.E., 1995. Oceanographic processes and sediment mixing on a sand flat in an enclosed sea, Manukau Harbour, New Zealand. Marine Geology 128 (3-4), 169-181, doi:10.1016/0025-3227(95)00097-I.

Fitzgerald, D.M., Fenster, M.S., Argow, B.A., Buynevich, I.V., 2008. Coastal impacts due to sea-level rise. Annual Review of Earth and Planetary Sciences 36, 601-647, doi:10.1146/annurev.earth.35.031306.140139.

Freeze, R.A., Cherry, J. A., 1979. Groundwater, Prentice-Hall, Englewood Cliffs, New Jersey, USA.

Gardner, L.R., 2005. Role of geomorphic and hydraulic parameters in governing pore water seepage from salt marsh sediments. Water Resources Research 41 (7), W07010, doi:10.1029/2004WR003671.

Gardner, L.R., 2007. Role of stratigraphy in governing pore water seepage from salt marsh 
sediments. Water Resources Research 43 (7), W07502, doi:10.1029/2006WR005338.

Gardner, L.R., Porter, D.E., 2001. Stratigraphy and geologic history of a southeastern salt marsh basin, North Inlet, South Carolina, USA. Wetlands Ecology and Management 9 (5) 371-385, doi:10.1023/A:1012060408387.

Gardner, L.R., Wilson, A.M., 2006. Comparison of four numerical models for simulating seepage from salt marsh sediments. Estuarine, Coastal and Shelf Science 69 (3-4), 427-437, doi:10.1016/j.ecss.2006.05.009.

Harvey, J.W., Germann, P.F., Odum, W.E., 1987. Geomorphological control of subsurface hydrology in the creek bank zone of tidal marshes. Estuarine, Coastal and Shelf Science 25 (6), 677-691, doi:10.1016/0272-7714(87)90015-1.

Hemond, H.F., Fifield J.L., 1982. Subsurface flow in salt marsh peat: A model and field study. Limnology and Oceanography 27 (1), 126-136.

Howes, B.L., Goehringer, D.D., 1994. Porewater drainage and dissolved organic carbon and nutrient losses through the intertidal creekbanks of a New England salt marsh. Marine Ecology Progress Series 114 (3), 289-301, doi: 10.3354/meps114289.

Howes, B.L., Howarth, R.W., Teal, J.M., Valiela, I., 1981. Oxidation-reduction potentials in a salt marsh: Spatial patterns and interactions with primary production. Limnology and Oceanography 26 (2), 350-360.

Hughes, C.E., Binning, P., Willgoose, G.R., 1998. Characterisation of the hydrology of an estuarine wetland. Journal of Hydrology $211 \quad(1-4), \quad 34-49$, doi:10.1016/S0022-1694(98)00194-2. 
Jeng, D.-S., Mao, X., Enot, P., Barry, D.A., Li, L., 2005. Spring-neap tide-induced beach water table fluctuations in a sloping coastal aquifer. Water Resources Research 41 (7), W07026, doi:10.1029/2005WR003945.

Li, H.L., Li, L., Lockington, D., 2005. Aeration for plant root respiration in a tidal marsh. Water Resources Research 41 (6), W06023, doi:10.1029/2004WR003759.

Li, L., Barry, D.A., Parlange, J.-Y., Pattiaratchi, C.B., 1997. Beach water table fluctuations due to wave run-up: Capillarity effects. Water Resources Research 33 (5), 935-945, doi:10.1029/96WR03946.

Li, L., Barry, D.A., Stagnitti, F., Parlange, J.-Y., Jeng, D.S. 2000. Beach water table fluctuations due to spring-neap tides: Moving boundary effects. Advances in Water Resources 23 (8), 817-824, doi:10.1016/S0309-1708(00)00017-8.

Marani, M., D’Alpaos, A., Lanzoni, S., Carniello, L., Rinaldo, A., 2007. Biologically-controlled multiple equilibria of tidal landforms and the fate of the Venice lagoon. Geophysical Research Letters 34, L11402, doi:10.1029/2007GL030178.

Marani, M., D’Alpaos, A., Lanzoni, S., Carniello, L., Rinaldo, A., 2010. The importance of being coupled: Stable states and catastrophic shifts in tidal biomorphodynamics. Journal of Geophysical Research 115, F04004, doi:10.1029/2009JF001600.

Marani, M., Silvestri, S., Belluco, E., Ursino, N., Comerlati, A., Tosatto, O., Putti, M., 2006. Spatial organization and ecohydrological interactions in oxygen-limited vegetation ecosystems. Water Resources Research 42 (6), W06D06, doi:10.1029/2005WR004582.

Mendelssohn, I.A., McKee, K.L., Patrick, W.H., 1981. Oxygen deficiency in Spartina 
alterniflora roots: Metabolic adaptation to anoxia. Science 214 (4519), 439-441, doi:10.1126/science.214.4519.439.

Moffett, K.B., Wolf, A., Berry, J.A., Gorelick, S.M., 2010. Salt marsh-atmosphere exchange of energy, water vapor, and carbon dioxide: Effects of tidal flooding and biophysical controls. Water Resources Research 46, W10525, doi:10.1029/2009WR009041.

Moffett, K.B., Gorelick, S.M., McLaren, R.G., Sudicky, E.A., 2012. Salt marsh ecohydrological zonation due to heterogeneous vegetation - groundwater - surface water interactions. Water Resources Research 48, W02516, doi:10.1029/2011WR010874.

Morris, J.T., 1988. Pathways and controls of the carbon cycle in salt marshes, In The Ecology and Management of Wetlands, edited by D. D. Hooks, pp. 497-510, Croom Helm, London, UK.

Novakowski, K.I., Torres, R., Gardner, L.R., Voulgaris, G., 2004. Geomorphic analysis of tidal creek networks. Water Resources Research 40 (5), W05401, doi:10.1029/2003WR002722.

Parlange, J.-Y., Brutsaert, W., 1987. A capillary correction for free surface flow of groundwater. Water Resources Research 23, 805-808.

Parlange, J.-Y., Stagnitti, F., Starr, J.L., Braddock, R.D., 1984. Free-surface flow in porous media and periodic solution of the shallow-flow approximation. Journal of Hydrology 70 (1-4), 251-263, doi:10.1016/0022-1694(84)90125-2.

Perillo, G.M.E., Minkoff, D.R., Piccolo, M.C., 2005. Novel mechanism of stream formation in coastal wetlands by crab-fish-groundwater interaction. Geo-Marine Letters 25 (4), 214-220, doi:10.1007/s00367-005-0209-2. 
Pfannkuch, H.O., Winter, T.C., 1984. Effect of anisotropy and groundwater system geometry on seepage through lakebeds: 1. Analog and dimensional analysis. Journal of Hydrology 75, 213-237, doi: 10.1016/0022-1694(84)90051-9.

Reeves, H.W., Thibodeau, P.M., Underwood, R.G., Gardner, L.R., 2000. Incorporation of total stress changes into the groundwater model SUTRA. Ground Water 38 (1), 89-98, doi:10.1111/j.1745-6584.2000.tb00205.x.

Robinson, C., Li, L., Barry, D.A., 2007. Effect of tidal forcing on a subterranean estuary. Advances in Water Resources 30 (4), 851-865, doi:10.1016/j.advwatres.2006.07.006.

Silvestri, S., Defina, A., Marani, M., 2005. Tidal regime, salinity and salt marsh plant zonation.

Estuarine, Coastal and Shelf Science 62 (1-2), 119-130, doi:10.1016/j.ecss.2004.08.010.

Simonini, P., Cola, S., 2002. Some pore pressure measurements at the marsh of S. Felice in the Venice lagoon, in Scientific Research and Safeguarding of Venice, CORILA Research Program 2001 Results, Ist. Veneto di Sci. Lett. ed Arti, Venice, Italy.

Teal, J.M., 1962. Energy flow in the salt marsh ecosystem of Georgia. Ecology 43 (4), 614-624.

Teo, H.T., Jeng, D.-S., Seymour, B.R., Barry, D.A., Li, L., 2003. A new analytical solution for water table fluctuations in coastal aquifers with sloping beaches. Advances in Water Resources 26 (12), 1239-1247, doi:10.1016/j.advwatres.2003.08.004.

Torres, R., Styles, R., 2007. Effects of topographic structure on salt marsh currents. Journal of Geophysical Research 112 (F2), F02023, doi:10.1029/2006JF000508.

Ursino, N., Silvestri, S., Marani, M., 2004. Subsurface flow and vegetation patterns in tidal environments. Water Resources Research 40 (5), W05115, doi:10.1029/2003WR002702. 
Valiela, I., Teal, J.M., 1979. The nitrogen budget of a salt marsh ecosystem. Nature 280 (5724), 652-656, doi:10.1038/280652a0.

van Genuchten, M.Th., 1980. A closed form equation for predicting the hydraulic conductivity of unsaturated soils. Soil Science Society of America Journal 44 (5), 892-898.

Voss, C.I., Provost, A.M., 2008. A model for saturated-unsaturated, variable-density ground-water flow with solute or energy transport, U.S. Geological Survey, $\begin{array}{lll}\text { Water-Resources } & \text { Investigations } & \text { Report }\end{array}$ (http://water.usgs.gov/nrp/gwsoftware/sutra.html).

Wang, Z., Feyen, J., Nielsen, D.R., van Genuchten, M.Th., 1997. Two phase flow infiltration equations accounting for air entrapment effects. Water Resources Research 33 (12), 2759-2767, doi:10.1029/97WR01708.

Wilson, A.M., Gardner L.R., 2006. Tidally driven groundwater flow and solute exchange in a marsh: Numerical simulations. Water Resources Research 42 (1), W01405. doi:10.1029/2005WR004302.

Wilson, A.M., Morris, J.T., 2012. The influence of tidal forcing on groundwater flow and nutrient exchange in a salt marsh-dominated estuary. Biogeochemistry 108 (1-3), 27-38, doi: $10.1007 / \mathrm{s} 10533-010-9570-\mathrm{y}$.

Winter, T.C., Pfannkuch, H.O., 1984. Effect of anisotropy and groundwater system geometry on seepage through lakebeds: 2. Numerical simulation analysis. Journal of Hydrology 75, 239-253, doi: 10.1016/0022-1694(84)90052-0.

Xin, P., Gibbes, B., Li, L., Song, Z., Lockington, D., 2010. Soil saturation index of salt marshes 
subjected to spring-neap tides: A new variable for describing marsh soil aeration condition. Hydrological Processes 24 (18), 2564-2577, doi:10.1002/hyp.7670.

Xin, P., Jin, G., Li, L., Barry, D.A., 2009. Effects of crab burrows on pore water flows in salt marshes. Advances in Water Resources 32 (3), 439-449, doi:10.1016/j.advwatres.2008.12.008.

Xin, P., Yuan, L.-R., Li, L., Barry D.A., 2011. Tidally driven multiscale pore water flow in a creek-marsh system. Water Resources Research 47, W07534, doi:10.1029/2010WR010110.

Yuan, L., Xin, P., Kong, J., Li, L., Lockington, D., 2011. A coupled model for simulating surface water and groundwater interactions in coastal wetlands. Hydrological Processes 25 (23), 3533-3546, doi: 10.1002/hyp.8079.

Zedler, J.B., Kercher, S., 2005. Wetland resources: status, trends, ecosystem services, and restorability. Annual Review of Environmental Resources 30, 39-74, doi:10.1146/annurev.energy.30.050504.144248.

Zhang, Y.L., Baptista, A.M., Myers, E.P., 2004. A cross-scale model for 3D baroclinic circulation in estuary-plume-shelf systems: I. Formulation and skill assessment. Continental Shelf Research 24 (18), 2187-2214, doi:10.1016/j.csr.2004.07.021.

Zimmerman, J.T.F., 1976. Mixing and flushing of tidal embayments in the western Dutch Wadden Sea part I: Distribution of salinity and calculation of mixing time scales. Netherlands Journal of Sea Research $10 \quad$ (2), 149-191, doi:10.1016/0077-7579(76)90013-2. 
Table 1. Summary of simulation cases and net flux results ${ }^{\text {a }}$

\begin{tabular}{|c|c|c|c|c|c|c|c|c|c|c|c|c|}
\hline \multirow{2}{*}{ Scenario } & \multicolumn{2}{|c|}{$\begin{array}{l}\text { Hydraulic conductivity } \\
\qquad\left(\mathrm{m} \mathrm{s}^{-1}\right)\end{array}$} & \multicolumn{2}{|c|}{ Porosity } & \multicolumn{2}{|c|}{$\begin{array}{l}\text { Compressibility } \\
\qquad\left(\mathrm{Pa}^{-1}\right)\end{array}$} & \multirow[t]{2}{*}{$S_{\text {Wres }}$} & \multirow{2}{*}{$\begin{array}{c}\alpha_{v} \\
\left(\mathrm{~m}^{-1}\right)\end{array}$} & \multirow[t]{2}{*}{$n$} & \multirow{2}{*}{$\begin{array}{l}Q_{\text {cr }} \\
\left(\mathrm{m}^{3}\right)\end{array}$} & \multirow{2}{*}{$\begin{array}{l}Q_{\mathrm{mc}} \\
\left(\mathrm{m}^{3}\right)\end{array}$} & \multirow{2}{*}{$\begin{array}{l}Q_{\mathrm{T}} \\
\left(\mathrm{m}^{3}\right)\end{array}$} \\
\hline & Upper layer & Lower layer & Upper layer & Lower layer & Soil matrix & Water & & & & & & \\
\hline Case 1 & $1.25 \times 10^{-6}$ & $1.23 \times 10^{-5}$ & 0.45 & 0.41 & $10^{-7}$ & $4.47 \times 10^{-10}$ & 0.15 & 2 & 1.41 & 9.63 & 1.96 & 11.59 \\
\hline Case 2 & $1.25 \times 10^{-6}$ & $1.23 \times 10^{-5}$ & 0.45 & 0.41 & 0 & 0 & 0.15 & 2 & 1.41 & 9.11 & 1.84 & 10.95 \\
\hline Case 3 & $1.25 \times 10^{-6}$ & $1.25 \times 10^{-6}$ & 0.45 & 0.45 & $110^{-7}$ & $4.47 \times 10^{-10}$ & 0.15 & 2 & 1.41 & 3.37 & 0.37 & 3.74 \\
\hline Case 4 & $1.25 \times 10^{-6}$ & $1.25 \times 10^{-6}$ & 0.45 & 0.45 & 0 & 0 & 0.15 & 2 & 1.41 & 3.18 & 0.35 & 3.53 \\
\hline
\end{tabular}

${ }^{\text {a }}$ For the upper and lower soil layers, the same parameter values were used for the compressibility and soil water retention curve.

$Q_{\mathrm{cr}}$ : total net efflux to the creek over the tidal period; $Q_{\mathrm{mc}}$ : total net efflux to the main channel over the tidal period; $Q_{\mathrm{T}}$ : total net efflux across the whole marsh system over the tidal period. 


\section{Figure captions}

Fig. 1. Diagram of the modeled creek-marsh system including major flow processes: (1) near-creek circulation, (2) meander-modulated circulation and (3) near-channel circulation (after Xin et al. (2011)). The contours show the marsh surface elevation. The scale of the $z$ axis is exaggerated by a factor of 8 . The layered soil stratigraphy is also illustrated.

Fig. 2. Schematic diagram of a conceptual model for overall exchange between a creek-marsh system and adjacent main channel. The dashed frame represents the creek-marsh system. The dotted lines indicate factors that were neglected in the present study.

Fig. 3. Flow field based on the phase-averaged result. Both figures show $2 \mathrm{D}$ flow on a cross-section parallel to the main channel $(y=100 \mathrm{~m})$. (a) is for the homogeneous marsh (Cases 3 and 4) and (b) is for the two-layer marsh (Cases 1 and 2). The black vectors are for the case without compressibility (Cases 2 and 4) and the red vectors are for the case with compressibility (Cases 1 and 3). Note that the flow fields with and without compressibility largely overlap. The blue line in (b) indicates the interface between the two layers.

Fig. 4. Phase-averaged flow fields. Both figures show the $2 \mathrm{D}$ flow on a cross-section perpendicular to the main channel $(x=-40 \mathrm{~m})$. (a) is for the homogeneous marsh (Cases 3 and 4) and (b) is for the two-layer marsh (Cases 1 and 2). The black vectors are for the case without compressibility (Cases 2 and 4) and the red vectors are for the 
case with compressibility (Cases 1 and 3). Note that the flow fields with and without compressibility largely overlap. The blue line in (b) indicates the interface between the two layers.

Fig. 5. (a) Tidal water level fluctuation relative to the local marsh platform elevation $(6.5 \mathrm{~m})$ at $y$ $=100 \mathrm{~m} .(\mathrm{b})$ and $(\mathrm{c})$, pore-water flow velocity over a tidal period at $x=15.74 \mathrm{~m}, y=$ $100 \mathrm{~m}$ and $z=6.26 \mathrm{~m}$ (in the upper soil layer): (b) is for the homogeneous marsh (Case 3) and (c) is for the two-layer marsh (Case 1). (d) and (e), Pore-water flow velocity over a tidal period at $x=4.02 \mathrm{~m}, y=100 \mathrm{~m}$ and $z=5.48 \mathrm{~m}$ (under the creek bank): (d) is for the homogeneous marsh (Case 3) and (e) is for the two-layer marsh (Case 1). Between the two vertical lines is the period during the marsh platform exposure.

Fig. 6. 3D particle traces through the marsh soil. The red lines are for the layered marsh (Case 1) and the blue lines are for the homogeneous marsh (Case 3). Details related to the particle movement are given in the table. The initial locations of the observation particles are also plotted in Figure 7.

Fig. 7. (a) and (c) show traces of particles initially released uniformly on the sediment surface (0.1 m soil depth). (b) and (d) show particle travel times. (a) and (b) are for the homogeneous marsh (Case 3) and (c) and (d) are for the two-layer marsh (Case 1). The color bars in (a) and (c) show the sediment surface elevation, and color bars in (b) and (d) show the travel time in Log (days). The initial locations of the four observation particles in Figure 6 are also shown in (a) and (c).

Fig. 8. Percentage of travel time greater than $t$. 
Fig. 9. Tidally averaged local flux (per unit area) across the marsh surface. All results are for a cross-section parallel to the main channel $(y=100 \mathrm{~m})$. The area between the two colored arrows is the area where $80 \%$ of the total influx occurred in each case.

Fig. 10. (a) Temporal changes of the tidal water level relative to local marsh surface elevations at various locations. (b) Surface water and groundwater exchange rate (net flux). In (b), negative values are for outflow and positive values are for inflow. Between the two vertical lines is the period during the marsh platform exposure.

Fig. 11. (a) Local net efflux (per unit area) across the interface of surface water and groundwater (in $\mathrm{m}^{3} / \mathrm{m}^{2} / \mathrm{d}$ ). Variations of net efflux (b) along the creek and (c) along the main channel.

Fig. 12. Sensitivity analysis on variations of net efflux along the creek (upper subplots) and along the main channel (lower subplots) for different (a) soil compressibility, (b) capillary rises and (c) hydraulic conductivities of the lower soil layer.

Fig. 13. Net efflux to the creek and the main channel over the tidal period versus the hydraulic conductivity contrast $\left(K_{\text {lower }} / K_{\text {upper }}\right)$. 


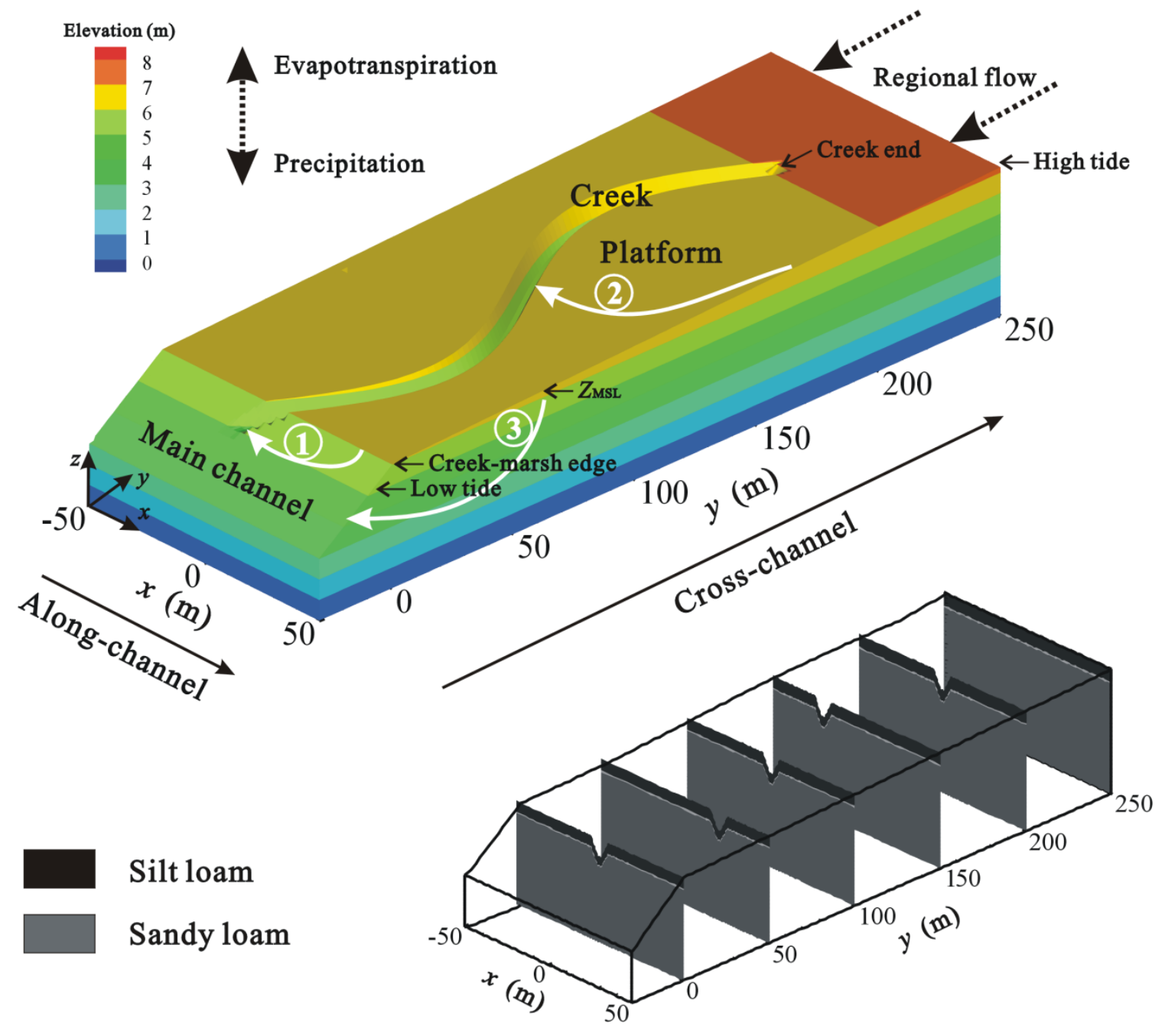

Fig. 1 


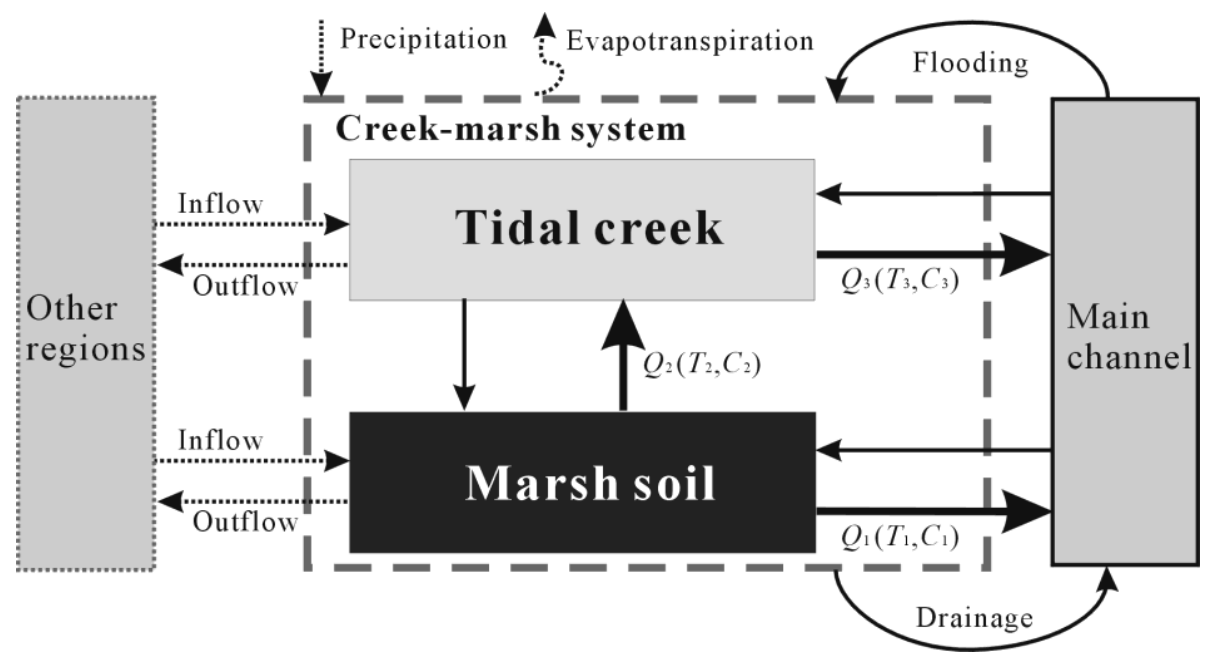

Fig. 2 

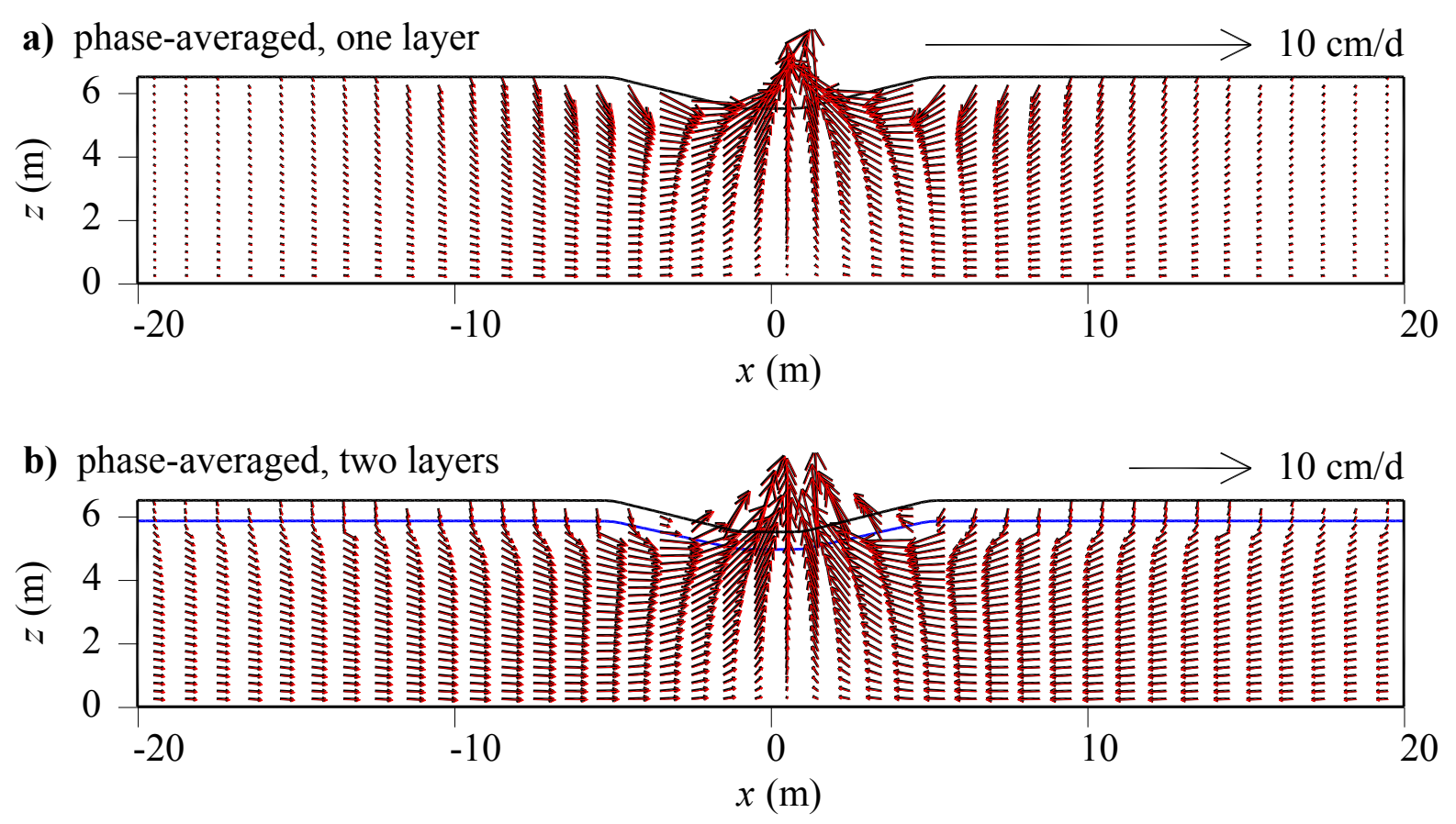

Fig. 3 

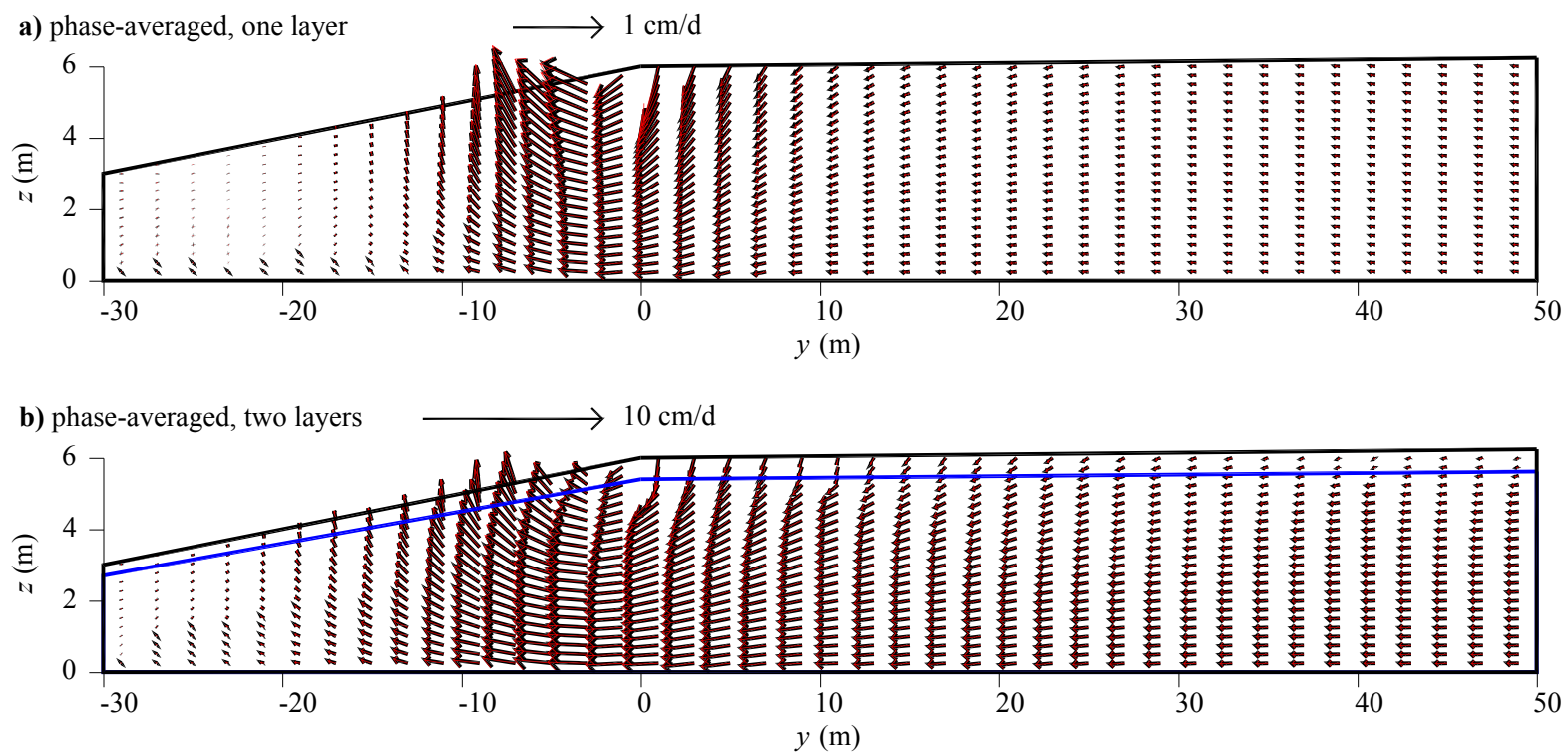

Fig. 4 
a)
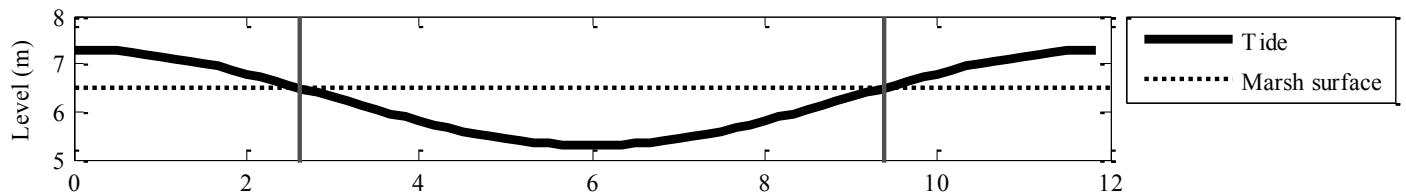

b)
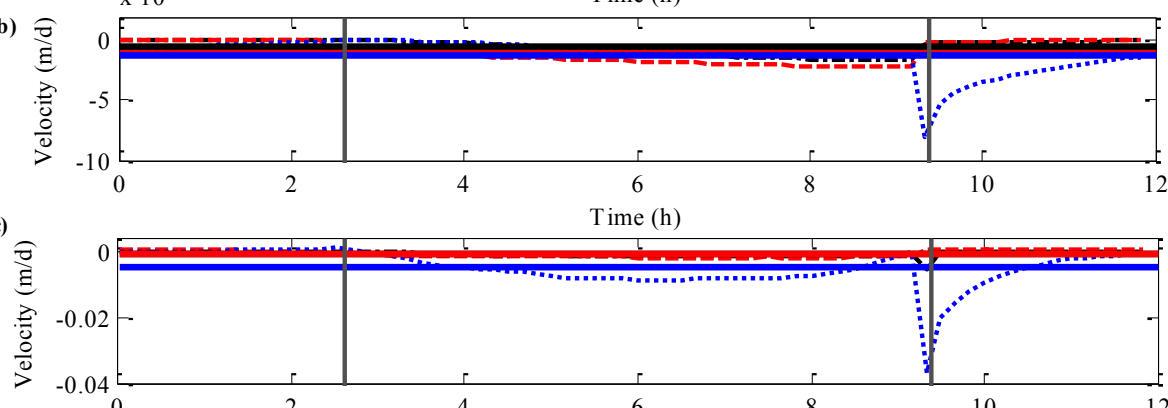

.

c)
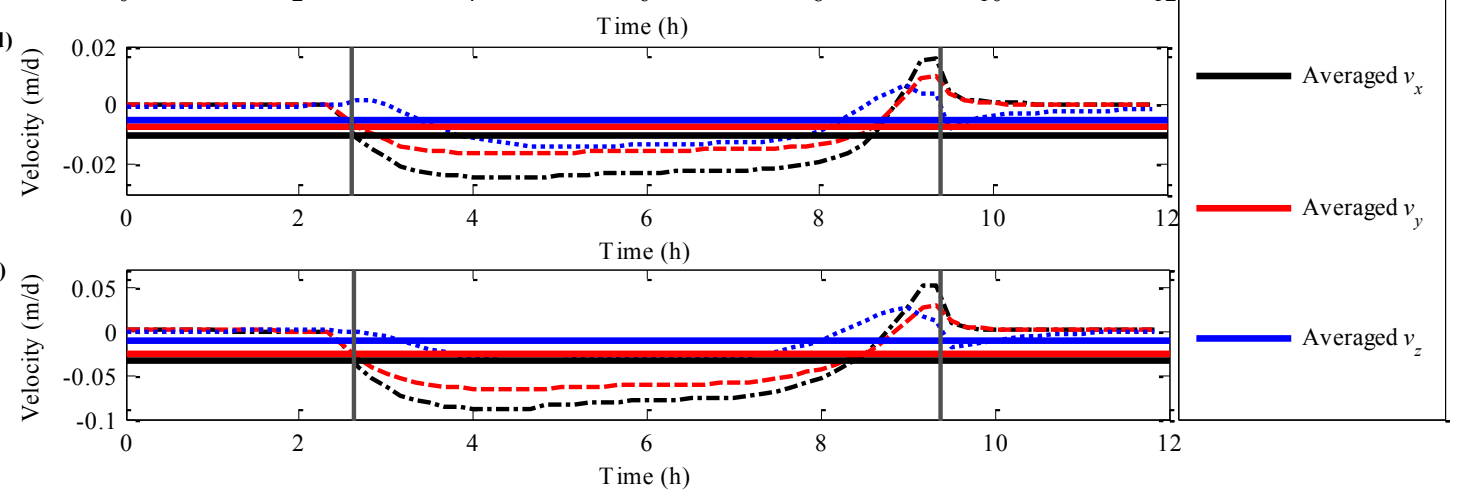

Fig. 5 


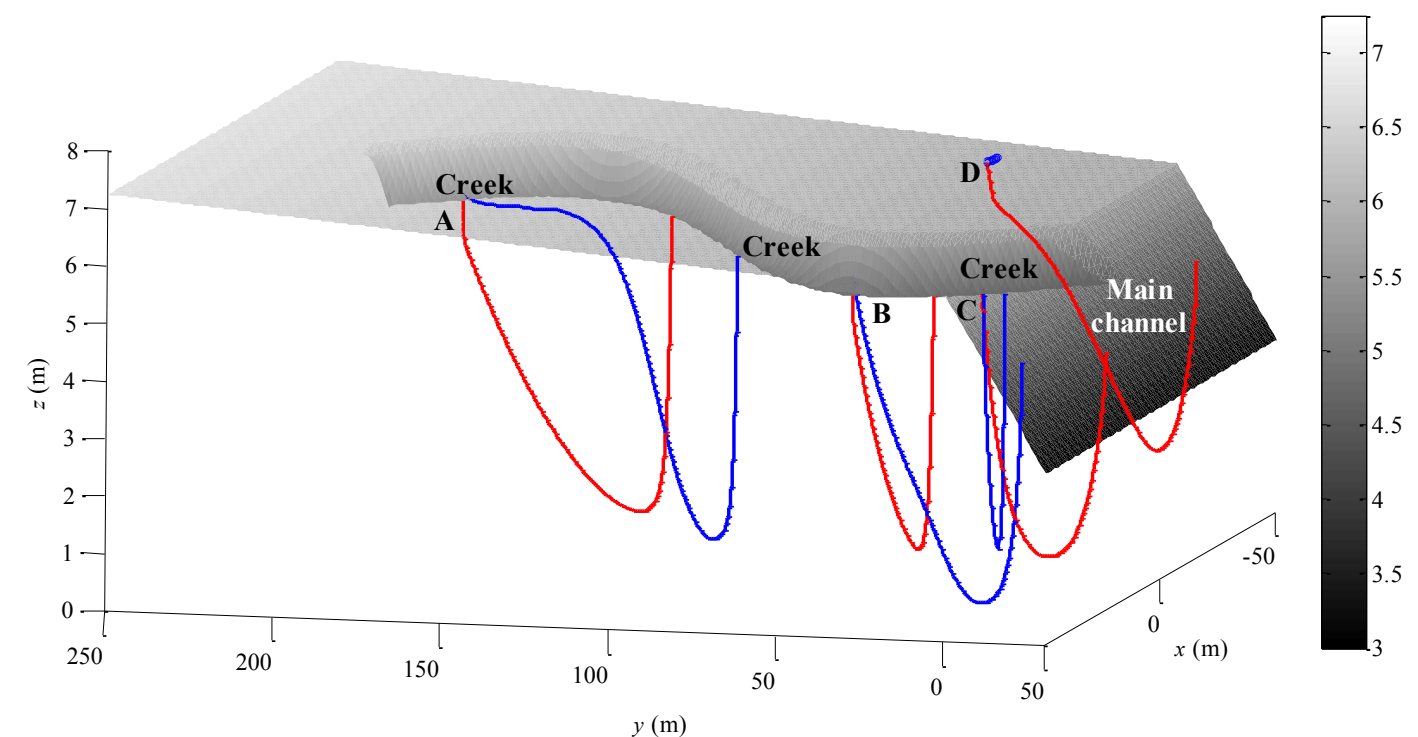

\begin{tabular}{|c|c|c|c|c|c|c|c|}
\hline \multirow{2}{*}{ Particle } & \multirow{2}{*}{$\begin{array}{c}\text { Initial location }(x, y) \\
(\mathrm{m})\end{array}$} & \multicolumn{2}{|c|}{$\begin{array}{c}\text { Exit location }(x, y) \\
(\mathrm{m})\end{array}$} & \multicolumn{2}{c|}{$\begin{array}{c}\text { Length of trace } \\
(\mathrm{m})\end{array}$} & \multicolumn{2}{c|}{$\begin{array}{c}\text { Travel time } \\
\left(10^{4} \mathrm{~d}\right)\end{array}$} \\
\cline { 2 - 8 } & & One-layer & Layered & One-layer & Layered & One-layer & Layered \\
\hline A & 20,165 & $3.9,93.9$ & $-14.5,126.2$ & 81.1 & 57.0 & 8.53 & 0.50 \\
\hline B & 40,35 & $36.8,-13.7$ & $15.6,27.4$ & 51.2 & 30.6 & 6.57 & 0.32 \\
\hline C & 20,10 & $7.5,11.6$ & $7.7,-18.6$ & 18.2 & 35.0 & 0.88 & 0.46 \\
\hline D & $-40,50$ & $-40.0,46.8$ & $-38.6,-13.7$ & 3.1 & 65.0 & 0.56 & 1.08 \\
\hline
\end{tabular}

Fig. 6 

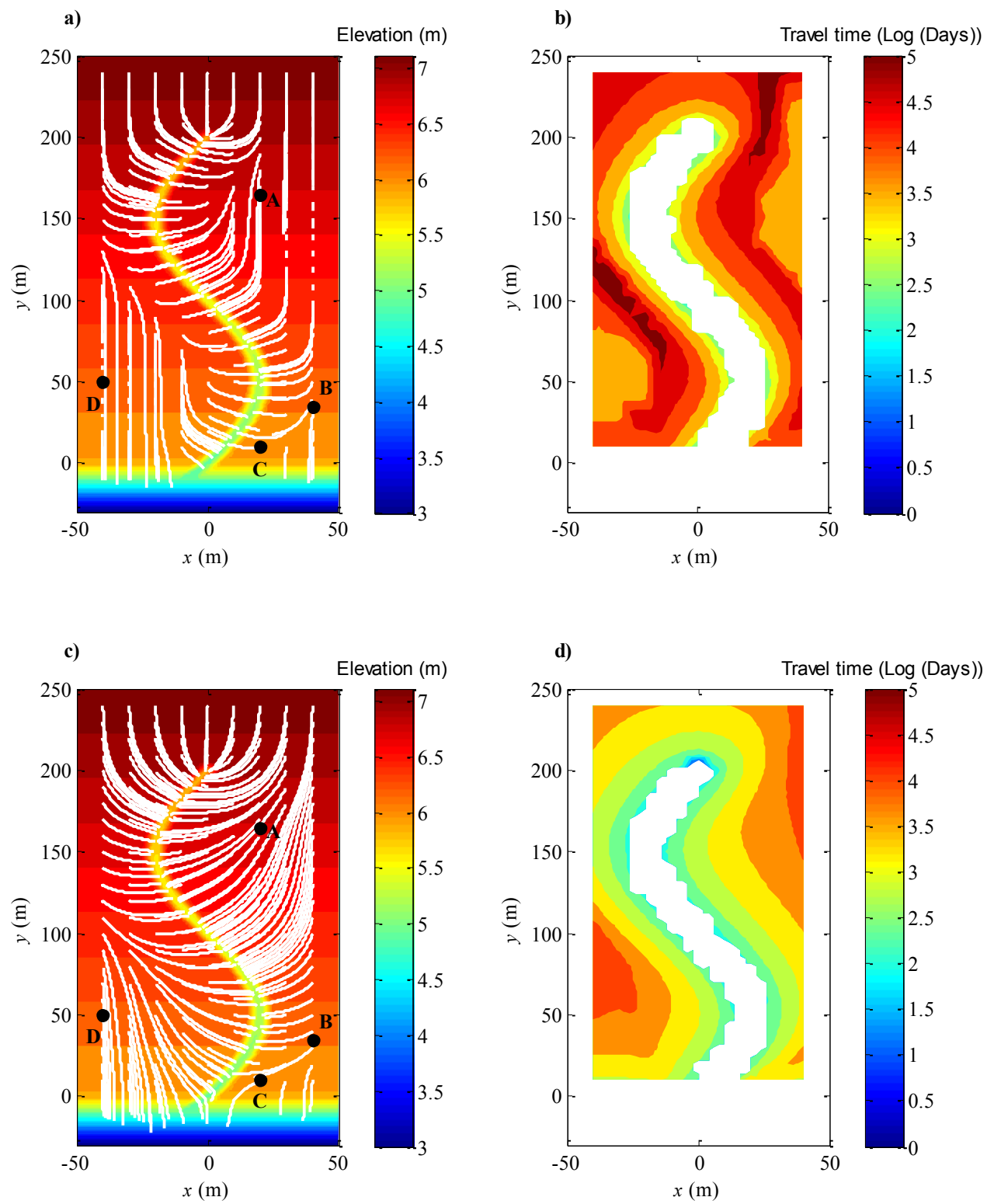

Fig. 7 


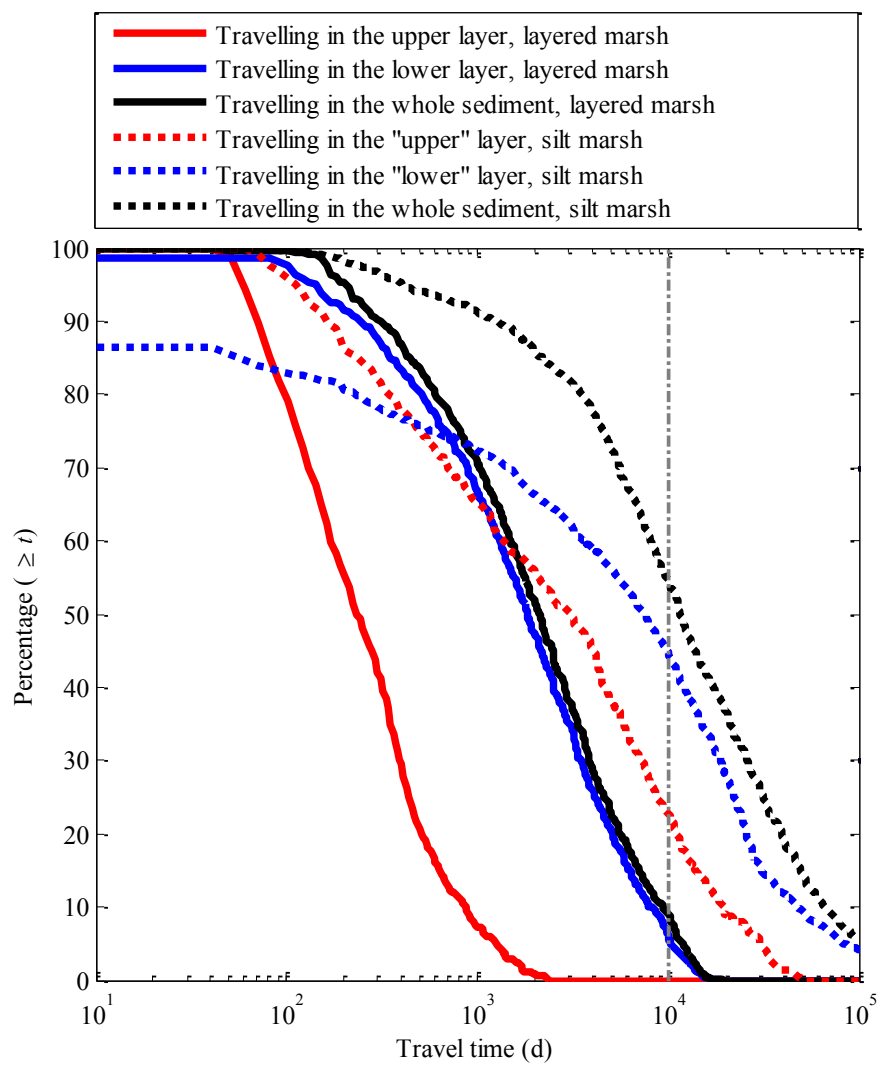

Fig. 8 


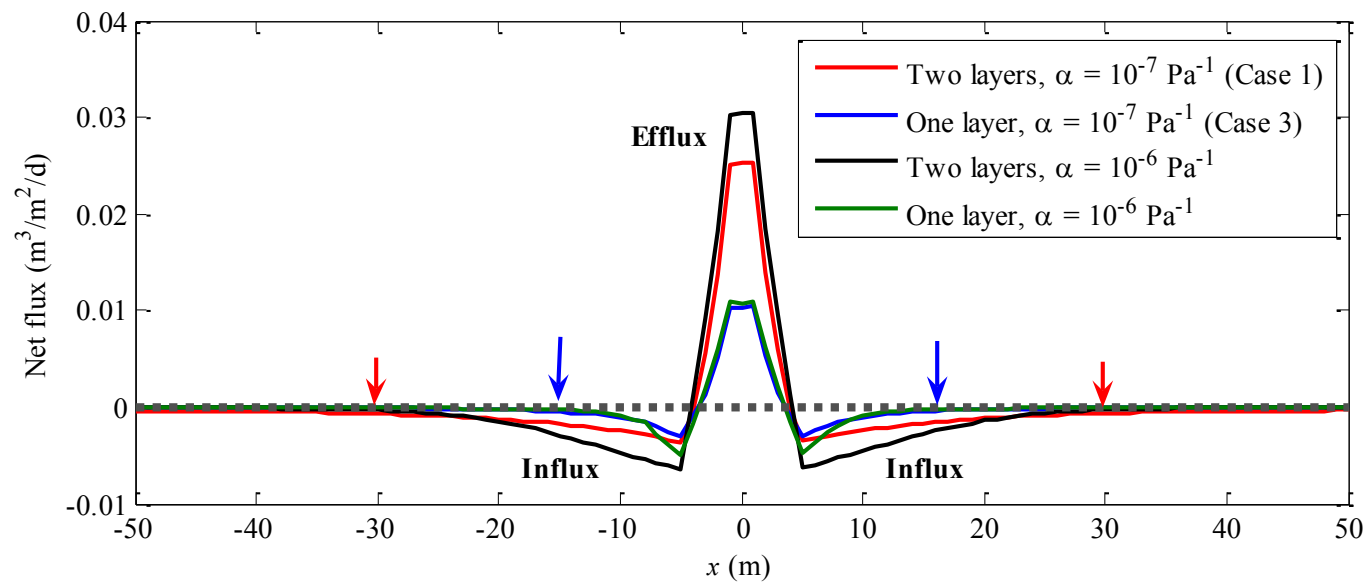

Fig. 9 
a)

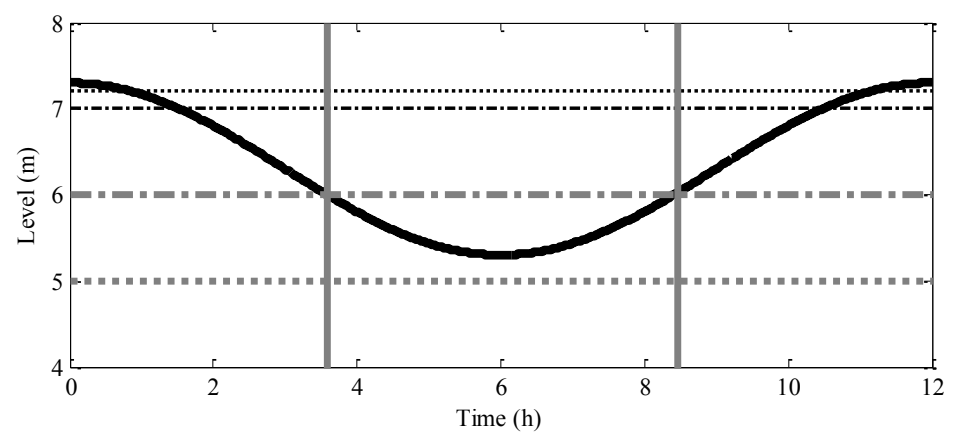

Tide

......... Highest marsh surface

-.-.- Maximum creek bank elevation

- - Marsh edge

" - " - Minimum creek bed elevation

b)

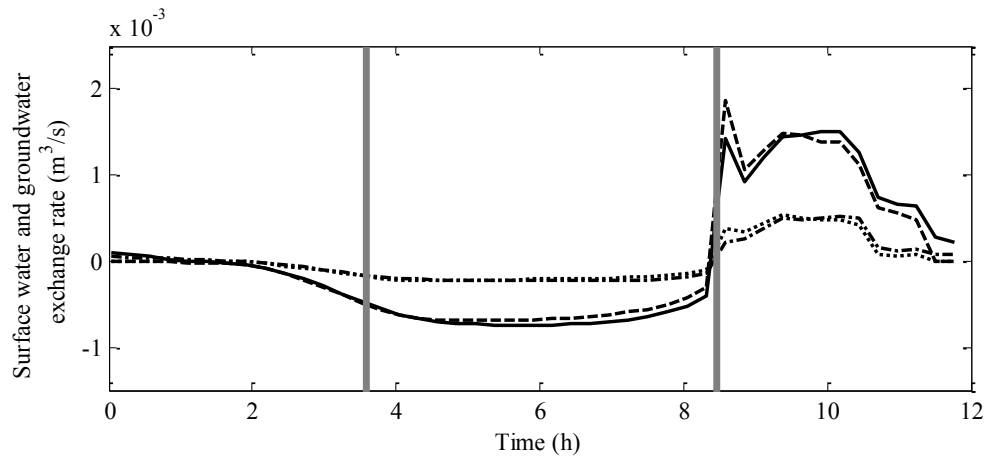

- Two layers, with compressibility ----- Two layers, without compressibility -.--One layer, with compressibility ……. One layer, without compressibility

Fig. 10 
a)

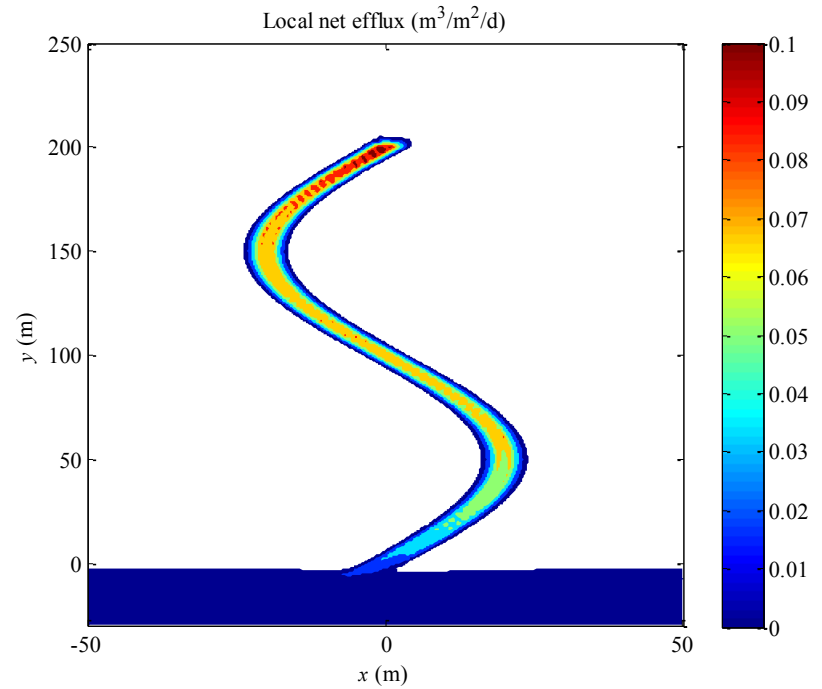

c)

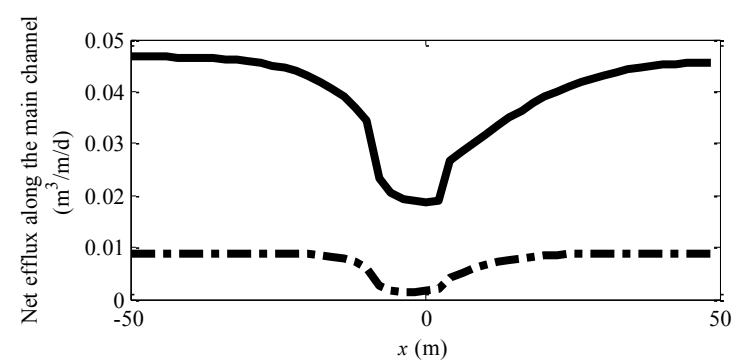

b)

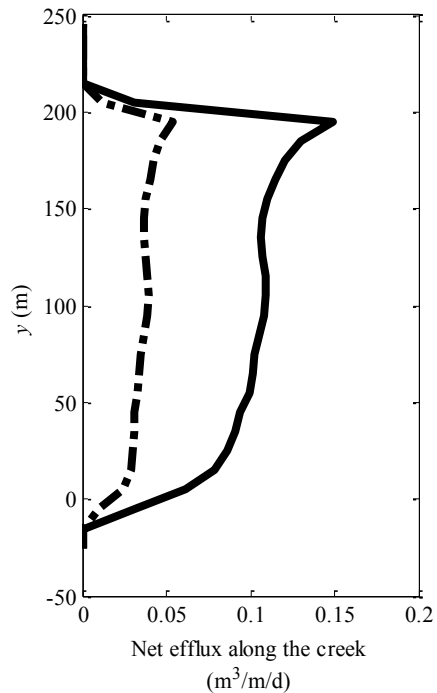

Two layers (Case 1)

- - One layer (Case 3)

Fig. 11 
a) Sensitivity of soil compressibility
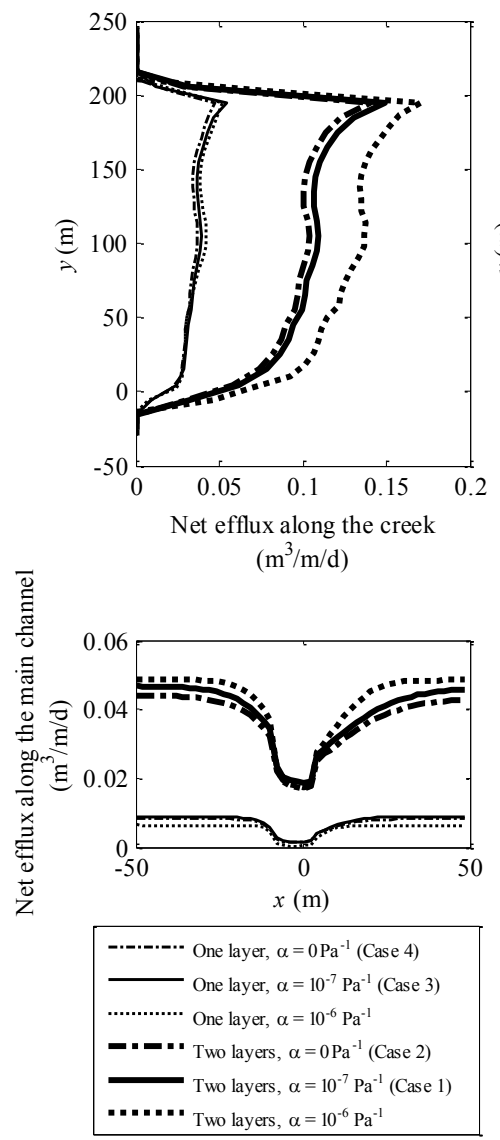

b) Sensitivity of capillary rise
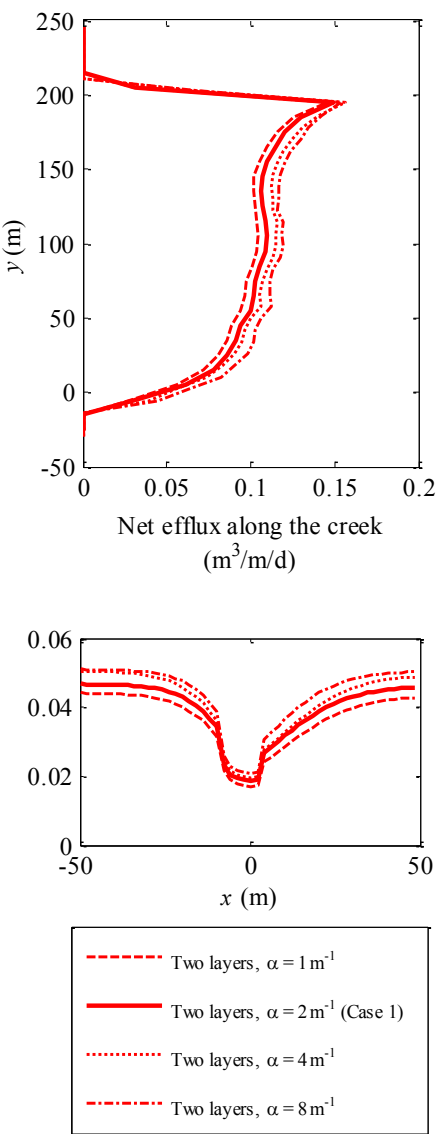

c) Sensitivity of hydraulic conductivity
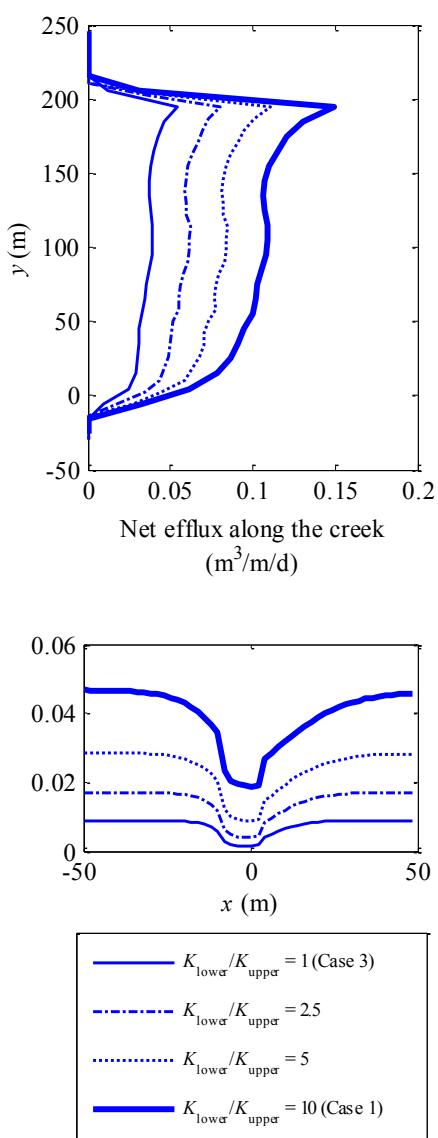

Fig. 12 


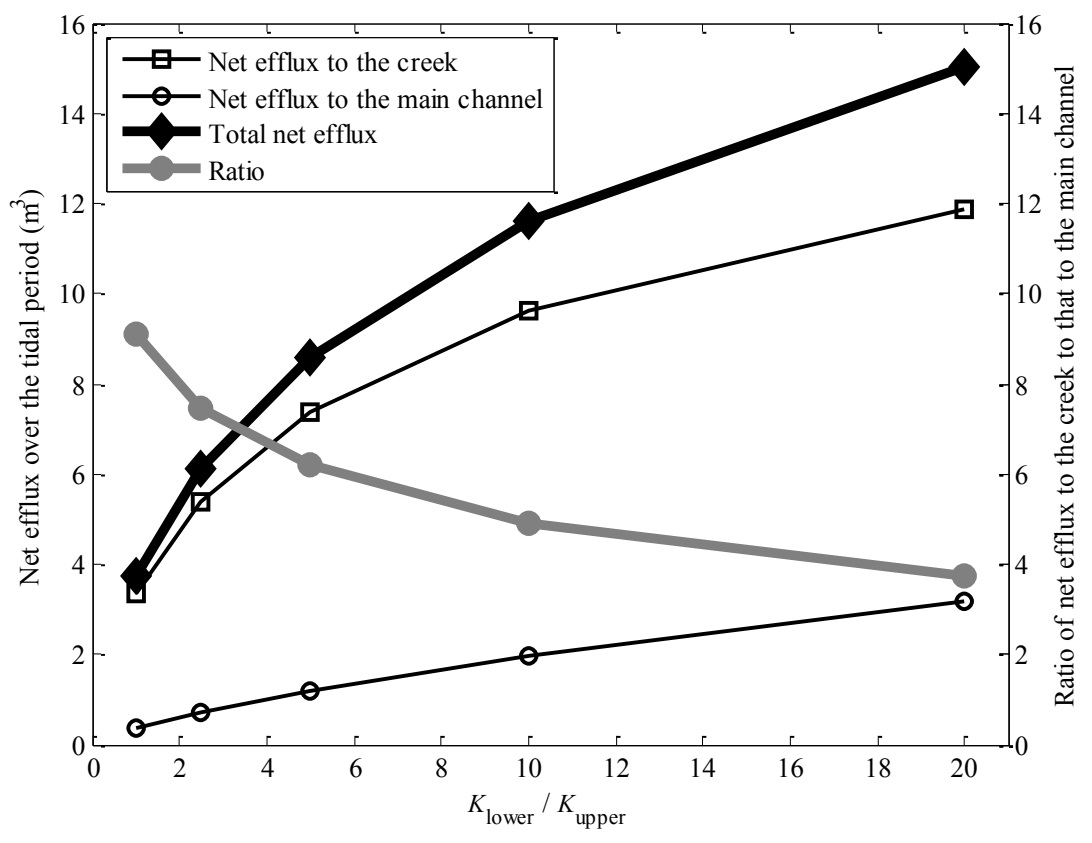

Fig. 13 